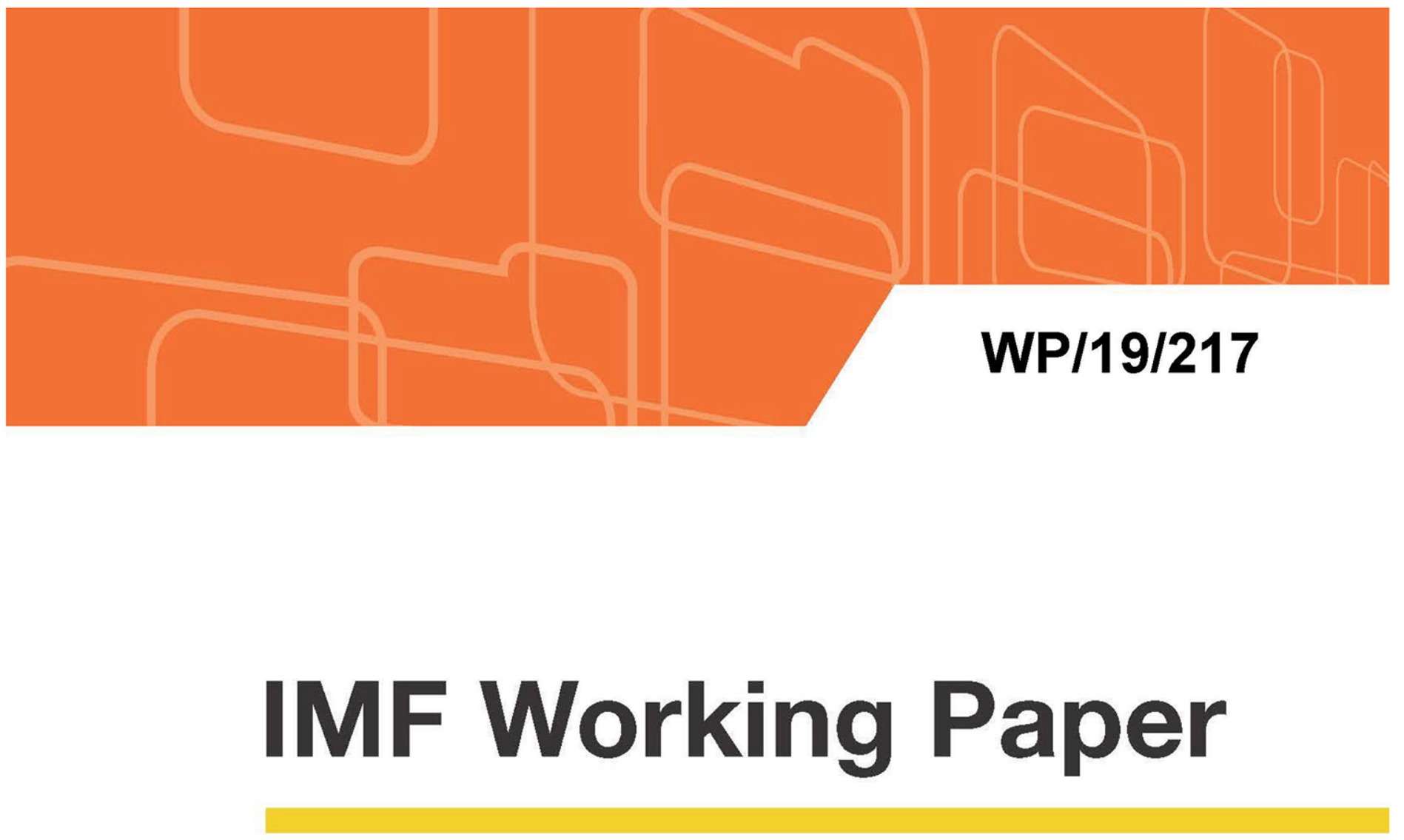

\title{
Macroeconomic Outcomes in Disaster-Prone Countries
}

by Alessandro Cantelmo, Giovanni Melina and Chris Papageorgiou

IMF Working Papers describe research in progress by the author(s) and are published to elicit comments and to encourage debate. The views expressed in IMF Working Papers are those of the author(s) and do not necessarily represent the views of the IMF, its Executive Board, or IMF management. 


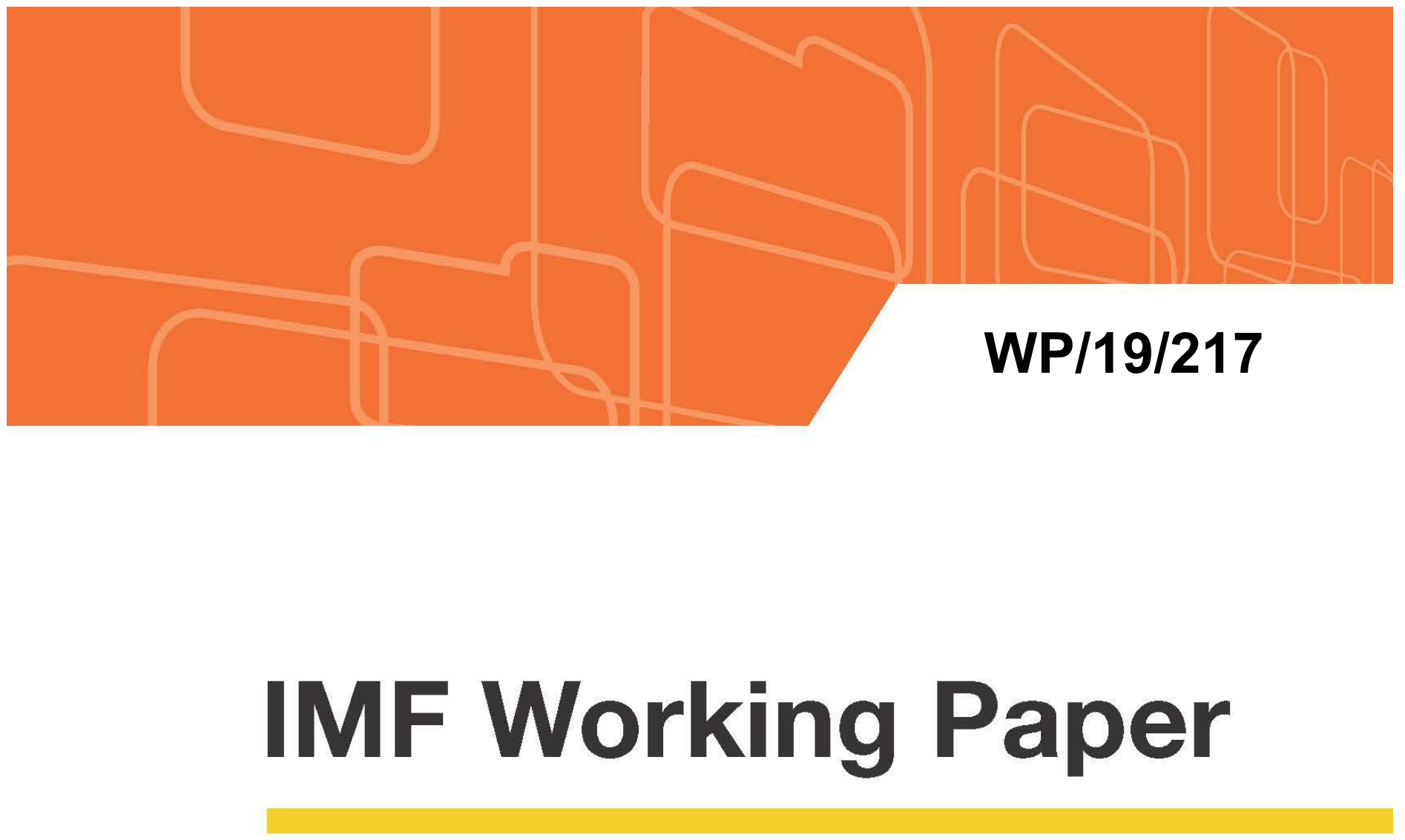

\section{Macroeconomic Outcomes in Disaster-Prone Countries}

by Alessandro Cantelmo, Giovanni Melina and Chris Papageorgiou

IMF Working Papers describe research in progress by the author(s) and are published to elicit comments and to encourage debate. The views expressed in IMF Working Papers are those of the author(s) and do not necessarily represent the views of the IMF, its Executive Board, or IMF management.

I N T E R N A T I O N A L M O N E T A R Y 


\title{
IMF Working Paper
}

\author{
Research Department
}

\section{Macroeconomic Outcomes in Disaster-Prone Countries ${ }^{1}$ \\ Prepared by Alessandro Cantelmo, Giovanni Melina and Chris Papageorgiou}

\author{
Authorized for distribution by Chris Papageorgiou
}

October 2019

\begin{abstract}
IMF Working Papers describe research in progress by the author(s) and are published to elicit comments and to encourage debate. The views expressed in IMF Working Papers are those of the author(s) and do not necessarily represent the views of the IMF, its Executive Board, IMF management of DFID.
\end{abstract}

\begin{abstract}
Using a dynamic stochastic general equilibrium model, we study the channels through which natural disaster shocks affect macroeconomic outcomes and welfare in disaster-prone countries. We solve the model using Taylor projection, a solution method that is shown to deal effectively with high-impact weather shocks calibrated in accordance to empirical evidence. We find large and persistent effects of weather shocks that significantly impact the income convergence path of disaster-prone countries. Relative to non-disaster-prone countries, on average, these shocks cause a welfare loss equivalent to a permanent fall in consumption of 1.6 percent. Welfare gains to countries that self-finance investments in resilient public infrastructure are found to be negligible, and international aid has to be sizable to achieve significant welfare gains. In addition, it is more cost-effective for donors to contribute to the financing of resilience before the realization of disasters, rather than disbursing aid after their realization.
\end{abstract}

JEL Classification Numbers: E62, F35, H54, H63, H84, O23, Q54.

Keywords: natural disasters, climate change, DSGE, resilient capital, international aid.

Authors’ E-Mail Addresses: alessandrocantelmo@gmail.com,gmelina@imf.org, cpapageorgiou@imf.org.

\footnotetext{
${ }^{1}$ We thank Jesus Fernandez-Villaverde, Amgad Hegazy, Seung Mo Choi, Ian Parry, Christiane Roehler, Susan Yang, colleagues at the IMF, and conference participants at the 2018 CEF in Milan, the 2018 CSAE in Oxford, the 2019 Scenarios Forum on Climate Change in Denver and the 2019 CESifo Macroeconomics and Finance Area Conference in Munich for extremely valuable comments and suggestions. We acknowledge funding from the U.K. Department of International Development (DFID). All remaining errors are ours.
} 


\section{Contents}

1 Introduction $\quad \underline{5}$

2 Disaster-Prone Developing Countries $\underline{8}$

3 The Model $\quad \underline{13}$

3.1 Households . . . . . . . . . . . . . . . . . . . . . . . . 14

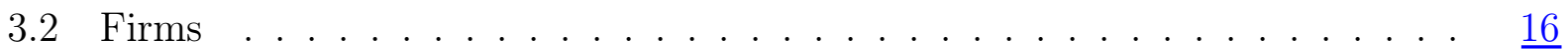

3.3 Government . . . . . . . . . . . . . . . . . . $\underline{17}$

3.4 Market Clearing and the Balance of Payments . . . . . . . . . . . $\underline{19}$

4 Calibration and Solution Method $\quad \underline{20}$

5 The Macroeconomic Effects of Natural Disasters and Climate Change 23

5.1 The Effects of a One-Off Natural Disaster . . . . . . . . . . . . . . $\underline{25}$

5.2 The Long-Run Effects of Natural Disasters . . . . . . . . . . . . . . . $\underline{27}$

5.3 The Effects of Climate Change . . . . . . . . . . . . . . $\underline{30}$

5.4 An Amplifier: The Sovereign Risk Premium . . . . . . . . . . . . . $\underline{30}$

5.5 Robustness Checks . . . . . . . . . . . . . . . . $\underline{33}$

6 Policy Responses $\quad \underline{35}$

6.1 Ex-Post International Aid . . . . . . . . . . . . . . . . $\underline{36}$

6.2 Ex-Ante Public Investment in Resilient Capital . . . . . . . . . . . . $\underline{38}$

7 Conclusions $\quad \underline{40}$

$\begin{array}{ll}\text { Appendix } & \text { I }\end{array}$

A Country Distribution and Statistics on Natural Disasters II

B The Most Damaging Natural Disasters $\quad \underline{\text { VI }}$

C The Stationary Model $\quad \underline{\text { VII }}$

\section{List of Tables}

1 Average Annual Probabilities of Natural Disasters per 1000 Squared Kilometers $(\%) \ldots \ldots \ldots \ldots \ldots \ldots \ldots$

2 Damages to GDP from Natural Disasters (\%). . . . . . . . . . . 11 
3 Baseline Calibration. . . . . . . . . . . . . . . . . . . 21

4 Average Effects of Natural Disaster Shocks in Disaster-Prone Countries. . . . $\underline{28}$

5 Average Effects of Climate Change in Disaster-Prone Countries. . . . . . . $\underline{31}$

6 Additional Effects of the Sovereign Risk Premium in Disaster-Prone Countries. $\underline{32}$

7 Robustness Checks. . . . . . . . . . . . . . . . . $\underline{34}$

A.1 Disaster-Prone Countries: Fourth Quartile (75\%-100\%) of the Annual Probability Distribution of Natural Disasters. . . . . . . . . . . . II

A.2 Non-Disaster-Prone Countries: Third Quartile (50\%-75\%) of the Annual Probability Distribution of Natural Disasters. . . . . . . . . . . . . III

A.3 Non-Disaster-Prone Countries: Second Quartile (25\%-50\%) of the Annual Probability Distribution of Natural Disasters. . . . . . . . . IV

A.4 Non-Disaster-Prone Countries: First Quartile (0\%-25\%) of the Annual Probability Distribution of Natural Disasters. . . . . . . . . . . $\underline{\mathrm{V}}$

B.1 The 20 Most Damaging Natural Disasters (1998-2017). . . . . . . . . VI

\section{List of Figures}

1 Distributions of Annual Probabilities of a Natural Disaster per 1000 Squared Kilometers and Damages to GDP per Natural Disaster. . . . . . . . . $\underline{9}$

2 Shares of Small and Non-Small Economies in each Country Group. . . . . . $\underline{12}$

3 Average Damages by Type of Disaster (\% of GDP). . . . . . . . . . $\underline{13}$

4 Impulse Responses of Selected Macroeconomic Variables to an Average Natural Disaster Shock in a Disaster-Prone Country. . . . . . . . . . . . $\underline{26}$

5 Impulse Responses of Selected Macroeconomic Variables to a Natural Disaster Shock of the Same Intensity as Hurricane Matthew Hitting Haiti in 2016. . . 27

6 Welfare Effects of Grants in Disaster-Prone Countries. . . . . . . . . . . . 37

$7 \quad$ Welfare Effects of Investment in Resilient Capital in Disaster-Prone Countries. $\underline{39}$ 


\section{Introduction}

The speed at which temperatures have changed globally over the past 40 years is unprecedented (Intergovernmental Panel on Climate Change, 2014) and further global warming may still take place, depending on how governments will be able to restrain greenhouse effects. ${ }^{1}$ In this paper, we focus on what is perhaps the most immediate and often dramatic impact of climate change: weather-related natural disasters such as cyclones, tornadoes and floods. More specifically, the aim of the paper is to examine the long-term effects of more frequent weather-related events on macroeconomic outcomes and welfare of disaster-prone countries (typically small states or low-income countries, LICs), ${ }^{2}$ and whether natural disasters and climate change can be considered elemental to their development process. Further, the paper investigates the channels that amplify the effects of natural disasters on these economies and seeks domestic and international policies that could help these countries become more resilient to weather events and mitigate welfare losses.

At a first approximation, natural disasters are not very different from the usual economic shocks typically embedded in macroeconomic models, except that they are created by mother nature (possibly with a human imprint that we safely assume exogenous to the economic activity of small states or LICs). However, there is one crucial difference: natural disasters can be very large. The bulk of the theoretical macroeconomic literature assumes, first, that shocks are small enough that a linear approximation of the model provides an accurate solution; and, second, that the economy will converge back to the initial deterministic steady state in the long run, absent further shocks. As we show subsequently, natural disaster shocks can be as big as $50 \%$ of GDP and climate change is likely to make them even more frequent and more catastrophic. ${ }^{3}$ Therefore, first, it would not be safe to study them in linearized models; second, it would be unrealistic to assume that the economy will converge back to the deterministic steady state after being subjected to large and frequent natural disaster shocks. In other words, agents' expectations about these shocks change the stochastic steady state of

\footnotetext{
${ }^{1}$ According to the United Nations Framework Convention on Climate Change (UNFCCC), as of March 2019, 195 UNFCCC members have signed the Paris agreement, which deals with greenhouse-gas-emissions mitigation, adaptation, and finance. The Paris Agreement's long-term goal is to keep the increase in global average temperature to well below $2{ }^{\circ} \mathrm{C}$ above pre-industrial levels.

${ }^{2}$ Appendix A provides the list of disaster-prone and non-disaster-prone developing countries used in the analysis. It also provides details about the most catastrophic natural disaster events experienced by some of these countries. Small states, due to their geographical position in tropical areas, are more exposed to extreme weather events than other developing countries. Rising temperatures increase both the probability and the magnitude of weather shocks, posing significant challenges for economic growth and fiscal positions of these countries. While natural disasters mostly affect small states, they also impact some low-income countries (LICs) as they are "small" in terms of per capita GDP rather than size, so even if a natural disaster hits only a specific area of the country, the damages in terms of GDP are sizable for the whole economy.

${ }^{3}$ Nonlinear effects of climate change have been documented by Burke et al. (2015), IMF (2017) and Nordhaus (2019).
} 
the economy, and long-run averages of macroeconomic aggregates diverge significantly from their initial steady state due to the sequence of these adverse shocks.

With this in mind, we base our analysis on a small-open economy dynamic stochastic general equilibrium (DSGE) model which embeds disaster shocks as in Gourio (2012), and is solved with Taylor projection, a solution method proposed by Levintal (2018) and FernandezVillaverde and Levintal (2018). Compared to the Fernandez-Villaverde-Levintal model, our setting abstracts from nominal rigidities, given our long-run viewpoint, and it is extended to capture aspects crucial to the analysis of the effects of natural disasters and policies to cope with them, namely public investment, external debt, the sovereign risk premium, resilient public infrastructure and international aid.

To our knowledge, this is the first paper that studies macro-fiscal issues related to weather shocks in a stochastic framework. ${ }^{4}$ The stochastic element is very important at least for two reasons. First, it is more realistic: while in deterministic models agents know the exact timing and magnitudes of disasters, in this more realistic setting, agents know the distribution of disaster shocks, with the realization of shocks being stochastic. Second, the stochastic steady state of the model depends on the distribution of the shocks. Therefore, while natural disasters are modeled as exogenous shocks, they have long-run effects on macroeconomic outcomes. In contrast, deterministic models can only have a deterministic steady state that, by construction, is independent of the distribution of exogenous shocks and, despite being buffeted by large shocks, the economy will eventually revert back to it. In our framework, given the forward-looking nature of agents and the presence of Epstein-Zin preferences in the model, the distribution of natural disaster shocks affects investment decisions even in the absence of an actual disaster realization.

Our main findings are as follows. First, weather shocks could significantly undermine the development process of many low-income countries and small states; insofar climate change continues to increase the magnitude and frequency of these destructive shocks, it is very likely to weigh to an even larger extent on the well-being or even mere existence of these and other larger countries. We make this point formally in the paper by running simulations with alternative calibrations of the distribution of disaster shocks. We find that only due to being subject to more frequent and powerful natural disasters, disaster-prone countries grow on average by 1 percent less a year than their non-disaster-prone peers. Second, we find sizable welfare losses in disaster-prone countries, with a permanent loss in consumption of 1.6 percent relative to non-disaster-prone ones. Third, assuming shifts in the disaster distributions similar to those observed in the past decade, climate change, in the long run,

\footnotetext{
${ }^{4}$ Previous contributions have provided interesting insights using deterministic (perfect foresight) solutions (see, e.g., Marto et al., 2018).
} 
may amplify the gap in growth to 3 percent a year while making the welfare losses about seven times larger. The main channels via which natural disasters propagate from a macroeconomic viewpoint, are the destruction of (private and public) capital modeled as a permanent one-off depreciation of the stock of existing capital and a temporary decline in productivity. Fourth, the fall in output also translates into lower government revenues and a higher public debt. On average, disaster-prone countries have a public debt 1.54 percentage points of GDP higher than non-disaster-prone countries, with this difference skyrocketing to 11 percent of GDP under a climate change scenario.

Finally, we consider policies aiming at mitigating the welfare losses. First, we let international donors disburse grants in the aftermath of natural disasters. Second, we introduce resilient public infrastructure making the assumption that a fraction of public infrastructure is not damaged by natural disasters but entails an additional fiscal cost that can be financed, in part or all, by donors. ${ }^{5}$ It turns out that disaster-prone countries can only mildly improve welfare by self-financing the investment in resilient capital. International aid is crucial to improve their welfare outcomes but it needs to exceed the amounts observed in recent history. Crucially, we find aid to be more effective when it finances ex-ante investment in resilient public infrastructure rather than accruing only in the aftermath of natural disasters. Indeed, to eliminate the welfare losses from natural disasters via grants that finance the extra cost of resilient infrastructure, donors would have to disburse less than a half the amount required to finance post-disaster intervention.

The paper is related to a growing literature that considers the wide-ranging effects of climate change on labor productivity, trade, health, mortality rates and conflict (see, Dell et al., 2014; Burke et al., 2015; Carleton and Hsiang, 2016; Heal and Park, 2016; Heal, 2017; and IMF, 2017 for comprehensive literature reviews). More specifically the paper falls closer to the emerging literature that introduces climate change into macroeconomic models. While most of the contributions introduce emissions and treat climate change as a negative externality that has to be taxed (see, e.g., Golosov et al., 2014; Hassler et al., 2016), we look at a particular consequence of climate change - weather-related natural disasters - which we consider exogenous to countries that have no material impact on emissions. From this point of view, the closest contributions to ours are those of Bevan and Adam (2016) and Marto et al. (2018). The former focus on the reconstruction of public capital in the aftermath of a natural disaster and on forms of insurance at the government level, while the latter focus on the trade-offs of investment in resilient capital versus post-disaster donor support. Both papers, however, use specific deterministic disaster shocks and perfect-foresight simulations.

The remainder of the paper is structured as follows. Section 2 reports some stylized

\footnotetext{
${ }^{5}$ In reality, resilient public capital is likely to still suffer damages, but to a much smaller extent.
} 
facts on weather-related shocks in disaster-prone countries vis-à-vis the rest of emerging and developing economies. Section 3 presents the model. Section 4 describes the calibration and the solution method. Section 5 discusses the main results of the analysis and provides robustness checks. Section 6 explores ex-post and ex-ante policy responses to mitigate the welfare losses from natural disasters. Section 7 concludes.

\section{Disaster-Prone Developing Countries}

In this section we outline stylized facts on natural disasters in developing countries. We construct statistics covering the last 20 years (1998-2017) by using the Emergency Events Database (EM-DAT), considering the following climate-related natural disasters: droughts, extreme temperatures, floods, fog, landslides, storms and wildfires. ${ }^{6}$ The EM-DAT database is compiled from various sources including UN, governmental and non-governmental agencies, insurance companies, research institutes and press agencies. Natural disasters are recorded if they meet at least one of the following criteria: (a) 10 or more people reported killed; (b) 100 or more people reported affected; (c) declaration of a state of emergency; (d) call for international assistance. Economic damages cover both direct and indirect losses related to the disaster. They include the amount of damage to property, crops, and livestock. For each disaster, the registered figure corresponds to the damage value at the moment of the event.

Our set of countries comprises low- and middle-income economies as classified by the World Bank (World Development Indicators), therefore 129 countries with a per capita Gross National Income below $\$ 12,055$ in 2017. For each country, we compute the annual probability of experiencing a natural disaster, which we use to define the distribution of countries. Since our dataset includes countries with either an extremely small (e.g. Pacific Islands) or large (e.g. China, India, Russia) surface, we follow IMF (2016) and adjust the number of events (and thus the annual probability) by the country's area. ${ }^{7}$ This boils down to reporting the annual probabilities per 1000 squared kilometers, to make comparisons meaningful. ${ }^{8}$ We then define disaster-prone countries those with an annual probability of experiencing a natural disaster in the top $25 \%$ of the distribution, while those in the remaining $75 \%$ are defined as non-disaster-prone countries. ${ }^{9}$

\footnotetext{
${ }^{6}$ EM-DAT: The Emergency Events Database - Universite Catholique de Louvain (UCL) - CRED, D. Guha-Sapir - www.emdat.be, Brussels, Belgium.

${ }^{7}$ Indeed, in larger countries, the number of natural disasters recorded in EM-DAT is much larger than for smaller countries.

${ }^{8}$ For brevity we will omit per 1000 squared kilometers in the rest of the paper when referring to the annual probability of a natural disaster.

${ }^{9}$ Appendix A reports the distribution of countries by annual probability of natural disaster. In total, our sample includes 2516 events (393 in disaster-prone countries, 2123 in non-disaster-prone countries).
} 
Figure 1: Distributions of Annual Probabilities of a Natural Disaster per 1000 Squared Kilometers and Damages to GDP per Natural Disaster.

(a) Distribution of Annual Probabilities of a Natural Disaster per 1000 Squared Kilometers (\%)

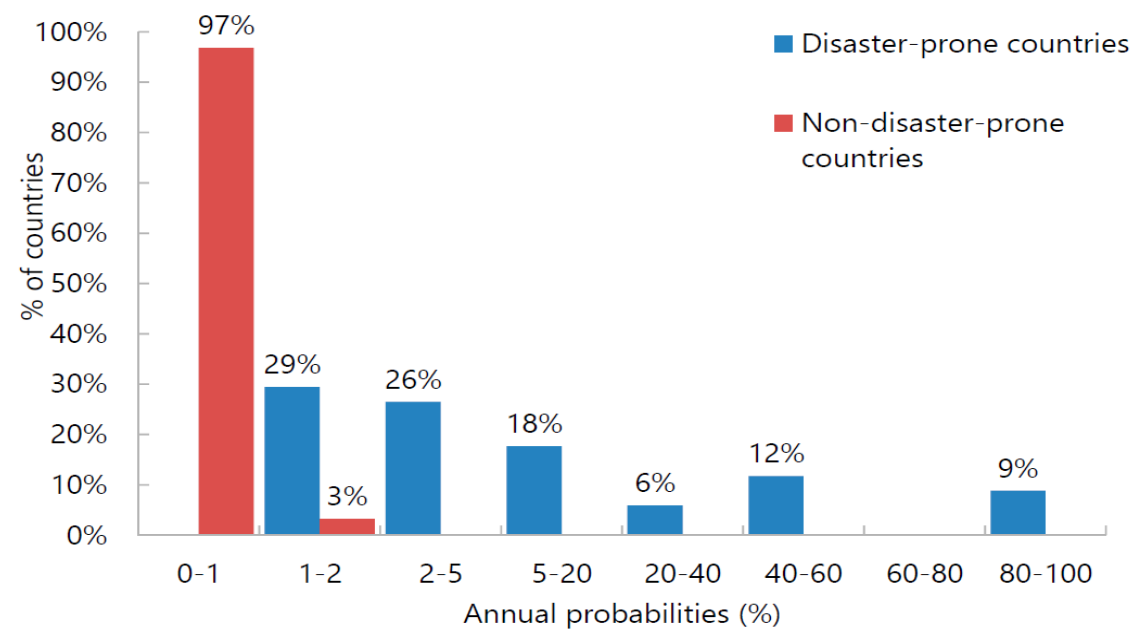

(b) Distribution of Damages per Natural Disaster (\% of GDP)

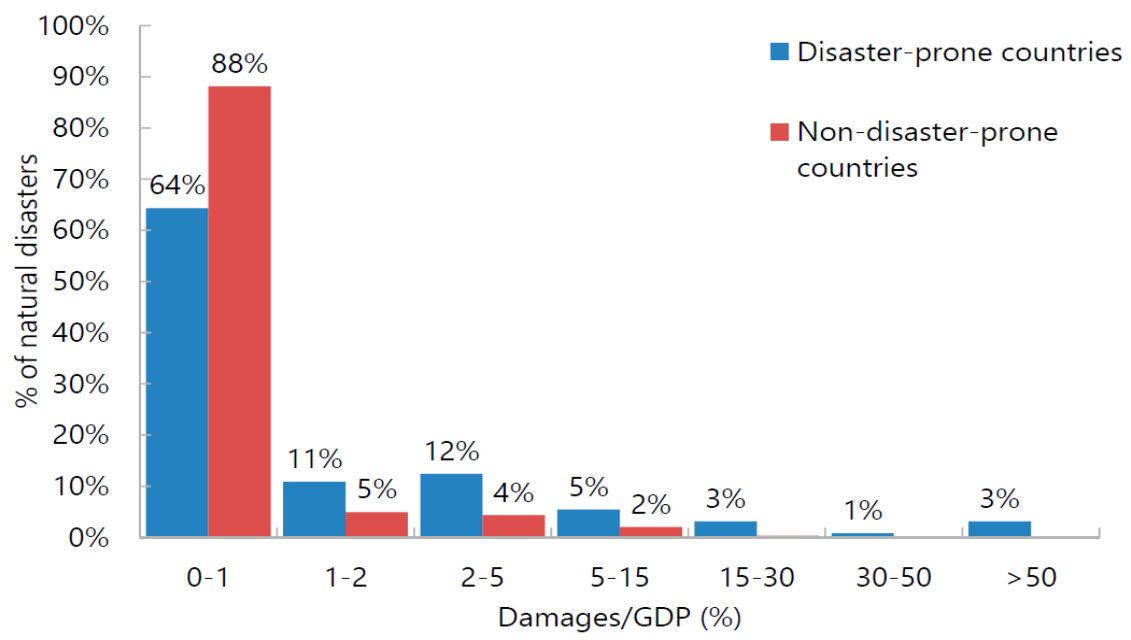

Sources: EM-DAT and authors' calculations.

Notes: Countries are ordered by the annual probability of a natural disaster per 1000 squared kilometers over the sample 1998-2017. Disaster-prone countries are those with an annual probability of a natural disaster in the top $25 \%$ of the distribution. Non-disaster-prone countries comprise the remaining $75 \%$ of countries. See Appendix A for the complete distribution. EM-DAT provides damages in US dollars. Damages in percent of GDP are obtained dividing damages by GDP of the year of the event. Distributions of damages (\% of GDP) are computed for each country group by using data for each single event over the sample 1998-2017.

Figure 1 reports the distributions of the annual probabilities and of the damages-to-GDP

Droughts, floods and storms represent $81 \%$ of the events. However, for the remaining natural disasters, only a few have economic damages reported, e.g., only one wildfire is reported for disaster-prone countries in 2017. Economic damages are available for about $33 \%$ of the events. 
Table 1: Average Annual Probabilities of Natural Disasters per 1000 Squared Kilometers $(\%)$.

\begin{tabular}{lc|cc}
\hline & Full sample & \multicolumn{2}{|c}{ Subsamples } \\
\cline { 2 - 4 } & $1998-2017$ & $1998-2007$ & $2008-2017$ \\
\hline Disaster-prone countries & 16.2 & 13.8 & 18.7 \\
Non-disaster-prone countries & 0.28 & 0.29 & 0.27 \\
\hline
\end{tabular}

Sources: EM-DAT and authors' calculations.

Notes: Countries are ordered by the annual probability of a natural disaster per 1000 squared kilometers over the sample 1998-2017. Disaster-prone countries are those with an annual probability of a natural disaster in the top $25 \%$ of the distribution. Non-disaster-prone countries comprise the remaining $75 \%$ of countries. See Appendix A for the complete distribution.

ratio of weather-related disasters in both country groups. It highlights that disaster-prone developing countries not only suffer from much more frequent events (by definition), but also much more powerful ones relative to their non-disaster-prone peers.

Indeed, Panel (a) shows that in $97 \%$ of non-disaster-prone countries the annual probability of being hit by a natural disaster is below 1 percent, while in the remaining $3 \%$ the annual probability is between $1 \%$ and $2 \%$ (the highest annual probability in non-disasterprone countries is $1.29 \%$, i.e. Djibouti). In contrast, no disaster-prone countries have an annual probability of experiencing a natural disaster below $1 \%$ and only $29 \%$ face an annual probability between $1 \%$ and $2 \%$. The remaining disaster-prone countries suffer from much more frequent natural disasters. For $26 \%$ of them the annual probability is between $2 \%$ and $5 \%$ while in $36 \%$ of disaster-prone countries the annual frequency of natural disasters is in the range 5\%-60\%. Importantly, there is a share of disaster-prone countries (9\%) with an annual probability between $80 \%$ and $100 \%$.

As far as damages are concerned, Panel (b) shows that $88 \%$ of natural disasters in nondisaster-prone countries destroy less than 1\% of GDP, and all the events cause damages not exceeding $15 \%$ of GDP. Conversely, disaster-prone countries tend to suffer larger damages as a fraction of GDP. For 23\% of events losses are between 1\% and 5\% of GDP, while for $12 \%$ of events, losses are above $5 \%$ of GDP.

Table 1 reports average annual disaster probabilities in the two country groups in the full sample (1998-2017) and in two ten-year subsamples (1998-2007 and 2008-2017). The average disaster probability in disaster-prone countries is 16\%, almost 60 times higher than in non-disaster-prone countries over the full sample. In addition, it is noteworthy that while the average disaster probability for non-disaster-prone countries barely changes in the two subsamples, for disaster-prone countries it rises from almost $14 \%$ in the first decade to around 
Table 2: Damages to GDP from Natural Disasters (\%).

\begin{tabular}{lcc|cc|cr}
\hline & Full sample & \multicolumn{3}{c}{ Subsamples } \\
\cline { 2 - 7 } & \multicolumn{2}{c|}{$1998-2017$} & $1998-2007$ & $2008-2017$ \\
\cline { 2 - 7 } & Average & Max & Average & Max & Average & Max \\
\hline Disaster-prone countries & 6.65 & 260 & 4.70 & 148 & 8.58 & 260 \\
Non-disaster-prone countries & 0.52 & 72.9 & 0.63 & 72.9 & 0.41 & 12.6 \\
\hline
\end{tabular}

Sources: EM-DAT and authors' calculations.

Notes: Countries are ordered by the annual probability of a natural disaster per 1000 squared kilometers over the sample 1998-2017. Disaster-prone countries are those with an annual probability of a natural disaster in the top $25 \%$ of the distribution. Non-disaster-prone countries comprise the remaining $75 \%$ of countries. See Appendix A for the complete distribution. EM-DAT provides damages in US dollars. Damages in percent of GDP are obtained dividing damages by GDP of the year of the event. Average and maximum damages (\% of GDP) are computed for each country group by using data for each single event over the sample 1998-2017 and over the two subsamples.

$19 \%$ in the more recent past ten years, increasing the divergence between the two country groups.

Table 2 highlights that, on average, disaster-prone countries experience disproportionately much larger damages per disaster than non-disaster-prone countries as a fraction of their GDP. Both in the full sample and in the two subsamples, the most damaging events recorded in disaster-prone countries (Hurricane Ivan that destroyed 148\% of Grenada's GDP in 2004 and Hurricane Maria that caused damages of the order of $260 \%$ of GDP in Dominica in 2017) were extremely more disastrous than the largest events recorded in non-disaster-prone countries (Hurricane Mitch that caused damages of the order of $73 \%$ of GDP in Honduras in 1998 and Cyclone Nargis that destroyed 12.6\% of GDP in Myanmar in 2008). Also average damages to GDP in disaster-prone countries became larger in the last decade (2008-2017) relative to the first decade of the sample (1998-2007), while in non-disaster-prone countries the average damages to GDP slightly fell. Therefore, the divergence between the two country groups has become more severe over time not only as regards the probability of experiencing a natural disaster, but also as regards its expected intensity.

One reason behind the stark difference in damages to GDP per natural disaster is that most disaster-prone countries either have a very small surface (e.g. small islands in the Pacific or the Caribbean) - and hence they are small by population (these are what the IMF defines as small states) - or they are small in economic terms (low-income countries) so that large and/or frequent disasters affect a large share of their GDP. Conversely, countries endowed with more natural shelters (larger countries) or in which the economy can better 
Figure 2: Shares of Small and Non-Small Economies in each Country Group.

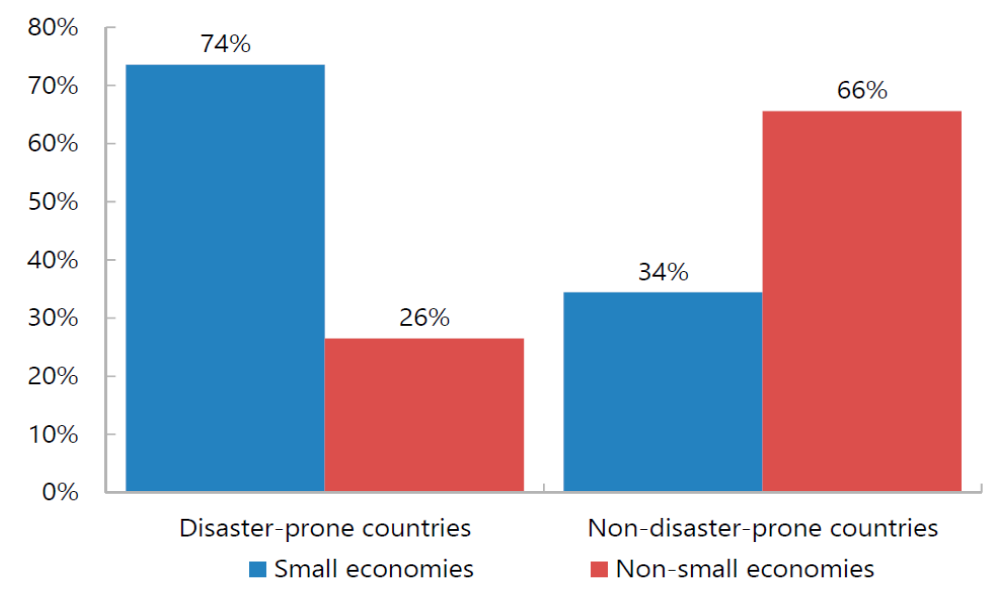

Sources: EM-DAT and authors' calculations.

Notes: Countries are ordered by the annual probability of a natural disaster per 1000 squared kilometers over the sample 1998-2017. Disaster-prone countries are those with an annual probability of a natural disaster in the top $25 \%$ of the distribution. Non-disaster-prone countries comprise the remaining $75 \%$ of countries. See Appendix A for the complete distribution. Small economies comprise small states and low-income countries. Small states are countries with a population below 1.5 million that are not advanced economies or highincome oil exporting countries (IMF). Low-income-countries are those with a GNI per capita below $\$ 995$ in 2017 (World Bank).

absorb weather shocks (countries other than low-income) mainly fall in the group of nondisaster-prone countries. We label the union between the sets of small states and low-income countries as small economies. ${ }^{10}$ Figure 2 highlights this point. While $74 \%$ of disaster-prone countries are small economies, the bulk of non-disaster-prone countries (66\%) falls in the non-small economies definition.

Finally, we consider the three most frequent and powerful natural disasters, i.e. droughts, floods and storms. Figure 3 shows that their impact is larger in disaster-prone countries, especially as far as storms are concerned. In disaster-prone countries, storms destroy 12 percent of GDP on average, against 1 percent of GDP in non-disaster-prone countries.

These stylized facts deserve a number of remarks. First, disaster-prone developing countries are not only much more exposed to natural disasters (by definition), but they suffer overwhelmingly larger losses per disaster than their non-disaster-prone peers, as a fraction of their GDP. Second, the effects of climate change have likely been more pronounced in

\footnotetext{
${ }^{10}$ The IMF defines small states those countries with a population below 1.5 million and that are not advanced economies (according to the World Economic Outlook's classification) or high-income oil exporting countries (according to the World Bank's classification), while the World Bank classifies as low-income countries those with a GNI per capita below $\$ 995$ in 2017. Appendix A provides details about whether each country is classified as a small economy or not, and whether it falls within the definition of a small state or a low-income country.
} 
Figure 3: Average Damages by Type of Disaster (\% of GDP).

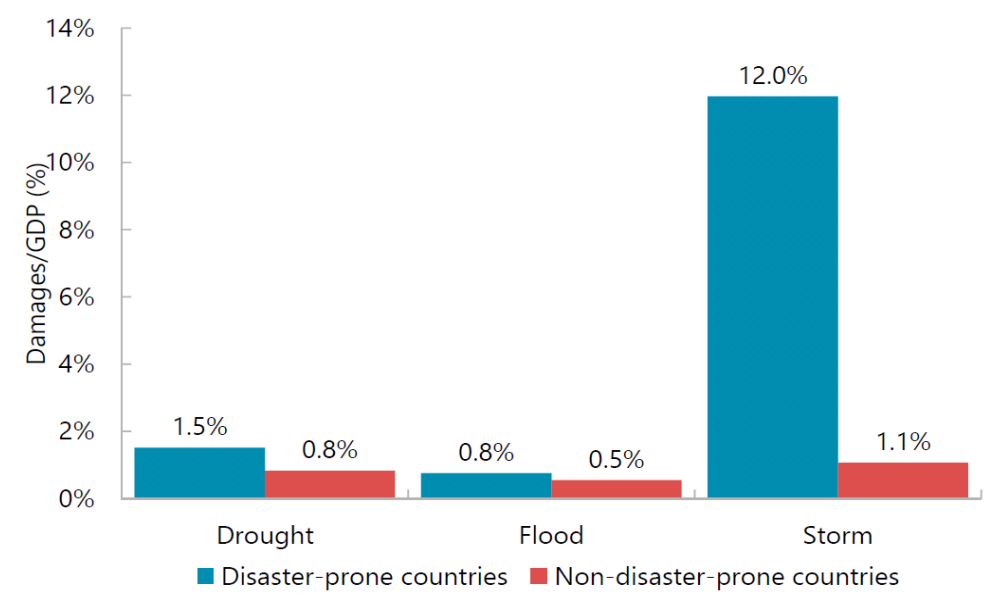

Sources: EM-DAT and authors' calculations.

Notes: Countries are ordered by the annual probability of a natural disaster per 1000 squared kilometers over the sample 1998-2017. Disaster-prone countries are those with an annual probability of a natural disaster in the top $25 \%$ of the distribution. Non-disaster-prone countries comprise the remaining $75 \%$ of countries. See Appendix A for the complete distribution. EM-DAT provides damages in US dollars. Damages in percent of GDP are obtained dividing damages by GDP in the year of the event. Distributions of damages (\% of GDP) are computed for each country group by using data for each single event over the sample 1998-2017. For each country group, average damages (\% of GDP) are computed by type of event.

disaster-prone countries, as they have recently experienced higher frequencies and magnitudes of climate-related events, signaling a divergence relative to their non-disaster prone peers along both dimensions. This evidence motivates our research question on whether these differences in the disaster distributions alone have (and will likely have) a significant weight on the growth path and welfare of disaster-prone countries relative to the rest of their peers. Fourth, the stark difference between the two country groups as regards the magnitude of damages to GDP is largely explained by the size of the economy. In fact, this is often much smaller in disaster prone countries due to geographical reasons or level of development. Last, the lion's share of damages are caused by storms, and this is not surprising given that the bulk of disaster prone countries are located in tropical areas.

\section{The Model}

To answer our research questions, we use a single-good small-open-economy real-businesscycle (RBC) model augmented with investment adjustment costs, stochastic trend growth and disaster shocks as in Gourio (2012) and Fernandez-Villaverde and Levintal (2018). The economy comprises a representative household supplying labor and deciding the optimal 
level of consumption and investment, while firms combine capital and labor to produce the single consumption good. Relative to the model employed in the contribution by FernandezVillaverde and Levintal (2018), our setting abstracts from nominal rigidities, given our focus on issues other than monetary policy and our long-run viewpoint.

Furthermore, we augment the model along four dimensions to capture transmission channels and policies important to study the macroeconomic effects of natural disasters in disaster-prone countries. First, we introduce a more detailed public sector whereby the government invests in public infrastructure and finances its expenditures by raising a consumption tax and accumulates debt. Therefore, the reconstruction of public capital in the aftermath of natural disasters entails a fiscal cost which is ultimately borne by households who pay a higher tax rate on consumption necessary to repay government debt. Then, we introduce a stylized small-open-economy dimension to allow for the accumulation of external government debt and to capture the evidence that countries hit by natural disasters face a higher sovereign risk premium, which further weighs on their public finances. Third, we allow the government to invest also in resilient public infrastructure to dampen the effects of natural disasters. Fourth, we introduce grants that can be injected from abroad to alternatively alleviate the fiscal burden in the aftermath of adverse weather shocks or to finance public investment in resilient capital. Given that the model has only one sector and does not explicitly include agriculture, it does not capture, e.g., damages to crops due to droughts or storms.

\subsection{Households}

The representative household exhibits recursive (or Epstein-Zin) preferences (Epstein and Zin, 1989)

$$
V_{t}^{1-\psi}=U_{t}^{1-\psi}+\beta E_{t}\left(V_{t+1}^{1-\gamma}\right)^{\frac{1-\psi}{1-\gamma}},
$$

where the period- $t$ utility $U_{t}$ is defined over consumption $c_{t}$ and labor $l_{t}, U_{t}=c_{t}\left(1-l_{t}\right)^{\nu}$, while $V_{t+1}$ is its continuation value. As noted by Caldara et al. (2012), the importance of recursive preferences is twofold. First, they allow for a distinction between the parameter governing risk aversion, $\gamma$, and the intertemporal elasticity of substitution $1 / \hat{\psi}$, where $\hat{\psi}=1-$ $(1+\nu)(1-\psi) \cdot{ }^{11}$ Second, they imply a trade-off between current and a certainty equivalent of future utility. Households therefore have preference for early $(\gamma>\hat{\psi})$ or later $(\gamma<\hat{\psi})$ resolution of uncertainty. These features are particularly appealing in our context where agents face the risk of natural disasters, which induces precautionary savings captured by

\footnotetext{
${ }^{11}$ The case of more standard constant relative risk aversion (CRRA) preferences can be achieved by setting $\gamma=1 / \hat{\psi}$.
} 
the recursive structure of preferences. Crucially, climate change, by increasing the risk faced by agents, generates further need for precautionary savings.

Each period, the household's budget constraint (in real terms) reads as:

$$
\left(1+\tau_{t}\right) c_{t}+x_{t}+b_{t+1}=w_{t} l_{t}+r_{t} k_{t}+R_{t-1} b_{t}+F_{t}+T_{t}
$$

where $\tau_{t}$ is a distortionary tax rate on consumption, $x_{t}$ denotes investment in capital, $w_{t}$ is the real wage, $r_{t}$ is the rental rate on capital $k_{t}, F_{t}$ are profits earned from firms, $T_{t}$ is a lump-sum transfer from the government and $b_{t}$ represents private bonds which pay a gross return, $R_{t}$.

The household determines the optimal capital stock, $k_{t}^{*}$, which depreciates at a rate $\delta$, and the investment $x_{t}$ needed to achieve it. However, changing investment plans entails a quadratic cost $S\left[\frac{x_{t}}{x_{t-1}}\right]=\frac{\kappa}{2}\left(\frac{x_{t}}{x_{t-1}} \hat{z}_{t}-\hat{z}\right)^{2}$ as in Christiano et al. (2005), where $\hat{z}_{t}$ is the technological stochastic trend growth. It follows that the law of motion of private capital reads as:

$$
k_{t}^{*}=(1-\delta) k_{t}+\left(1-S\left[\frac{x_{t}}{x_{t-1}}\right]\right) x_{t},
$$

with

$$
\log k_{t}=\log k_{t-1}^{*}-d_{t} \theta_{t}
$$

We follow Gourio (2012) and Fernandez-Villaverde and Levintal (2018) by defining $k_{t}$ as the actual capital stock at the beginning of period $t$, which equals the optimal stock of capital chosen in the previous period net of the natural disaster shock. Specifically, $d_{t}$ is an i.i.d. binary variable that takes value of 1 with probability $p_{d}$ in case of disaster, and takes value of 0 with probability $1-p_{d}$ in case of no disaster. If a natural disaster hits, $d_{t}=1$ and the actual capital $k_{t}$ permanently depreciates by an amount determined by $\theta_{t}$. In particular, $\theta_{t}$ evolves according to

$$
\log \theta_{t}=\left(1-\rho_{\theta}\right) \log \bar{\theta}+\rho_{\theta} \log \theta_{t-1}+\sigma_{\theta} \epsilon_{\theta, t}
$$

which captures the time-varying dimension of the disaster risk, with $\bar{\theta}$ governing the expected output loss caused by the disaster shock. Term $\epsilon_{\theta, t}$ is an i.i.d. normally distributed shock with mean zero and standard deviation 1 , while $\sigma_{\theta}$ scales volatility. As noted by FernandezVillaverde and Levintal (2018), this makes the process defined in equation (5) resembling that of stochastic volatility.

Optimal choices of consumption, financial assets, capital stock, investment and labor supply are taken to maximize utility (1) subject to (2), and (3) lead to the following first- 
order conditions:

$$
\begin{aligned}
1 & =E_{t} M_{t+1} R_{t}, \\
w_{t} & =\nu \frac{c_{t}}{1-l_{t}}, \\
q_{t} & =E_{t}\left(M_{t+1} \exp \left(-d_{t+1} \theta_{t+1}\right)\left[r_{t+1}+q_{t+1}(1-\delta)\right]\right), \\
1 & =q_{t}\left[1-S\left[\frac{x_{t}}{x_{t-1}}\right]-S^{\prime}\left[\frac{x_{t}}{x_{t-1}}\right] \frac{x_{t}}{x_{t-1}}\right]+ \\
& +E_{t} M_{t+1} q_{t+1} S^{\prime}\left[\frac{x_{t+1}}{x_{t}}\right]\left(\frac{x_{t+1}}{x_{t}}\right)^{2} .
\end{aligned}
$$

Equation (6) is a standard Euler Equation of consumption, where $M_{t+1} \equiv \beta \frac{\lambda_{t+1}}{\lambda_{t}}$ is the stochastic discount factor, $\lambda_{t}$ is the Lagrange multiplier on the budget constraint (2). Equation (7) represents the marginal rate of substitution between consumption and leisure, while equations (8) and (9) define the asset price and investment decision, respectively.

\subsection{Firms}

The economy features a continuum $i \in(0,1)$ of firms that choose labor and private capital to maximize profits:

$$
\max _{k_{i, t}, l_{i,}}\left[y_{i, t}-w_{i, t} l_{i, t}-r_{i, t} k_{i, t}\right] .
$$

The production function is Cobb-Douglas, with $\alpha \in[0,1]$ being the total capital share, while $\alpha_{g} \in[0,1]$ represents the share of public capital in the total capital stock:

$$
y_{i, t}=A_{t}\left(k_{i, t}^{1-\alpha_{g}} \bar{k}_{g, t}^{\alpha_{g}}\right)^{\alpha} l_{i, t}^{1-\alpha}
$$

Aggregate technology follows a random walk process with a drift and is subject both to a normally distributed shock, $z_{A, t}$, and the disaster shock:

$$
\log A_{t}=\log A_{t-1}+\Lambda_{A}+z_{A, t}-(1-\alpha) d_{t} \theta_{t}
$$

where $z_{A, t}$ follows an $\operatorname{AR}(1)$ process with persistence $\rho_{z a}$, standard deviation $\sigma_{z a}$ and $\epsilon_{a, t} \sim$ $N(0,1)$ :

$$
\log \left(\frac{z_{A, t}}{z_{A}}\right)=\rho_{z a} \log \left(\frac{z_{A, t-1}}{z_{A}}\right)+\sigma_{z a} \epsilon_{a, t} .
$$

We follow Fernandez-Villaverde and Levintal (2018) in rescaling the disaster variables in the process of aggregate technology $(12)$ by $(1-\alpha)$ to ensure that disasters reduce capital and total output by the same factor $\left(d_{t} \theta_{t}\right)$. 
This structure of the supply side of the economy has two peculiarities. First, productivity is affected by disaster shocks along with capital. Second, differently from FernandezVillaverde and Levintal (2018), we allow public capital $\bar{k}_{g, t}$ to enter the production function, which is important for the study of the effects of natural disasters, as specified in the next section.

Firms' optimizing conditions equate factors' price to marginal products of private capital and labor:

$$
\begin{aligned}
r_{t} & =\alpha\left(1-\alpha_{g}\right) \frac{y_{t}}{k_{t}}, \\
w_{t} & =(1-\alpha) \frac{y_{t}}{l_{t}}
\end{aligned}
$$

\subsection{Government}

The government conducts fiscal policy by allocating expenditure to interest payments on existing debt $R_{t} b_{g, t}$-where $R_{t}$ is the gross real interest rate paid on government bonds $b_{g, t}$-government consumption $g$ (which, for simplicity, we assume to be constant), and investment in public capital. The baseline simulations assume only investment in standard public infrastructure $x_{g, t}$, while we let the government also invest in public capital resilient to natural disasters $x_{g a, t}$ when we study adaptation policies (Section 6.2).

To introduce these policies, we assume that part of the total public capital stock is completely resilient to natural disasters, thus mitigating the damages to output. ${ }^{12}$ In general, the total public capital stock $\bar{k}_{g, t}$ aggregates standard and resilient capital according to:

$$
\bar{k}_{g, t}=k_{g, t}+k_{g a, t-1},
$$

thus assuming that the two types of public capital are perfect substitutes as in Marto et al. (2018). Similarly to private capital, the actual standard public capital stock $k_{g, t}$ is the previous period's stock $k_{g, t-1}^{*}$ net of natural disasters:

$$
\begin{aligned}
k_{g, t}^{*} & =\left(1-\delta_{g}\right) k_{g, t}+x_{g, t}, \\
\log k_{g, t} & =\log k_{g, t-1}^{*}-d_{t} \theta_{t} .
\end{aligned}
$$

Conversely, resilient capital is not damaged by natural disasters and hence follows a more

\footnotetext{
${ }^{12}$ The mitigating role of resilient capital has already been highlighted by Marto et al. (2018) by studying a one-time extreme natural disaster in the context of a deterministic model where resilient capital mitigates the damages because it has a lower depreciation rate than standard capital. Here, for simplicity, we assume the same depreciation rate $\delta_{g} \in[0,1]$ for both types of public capital, although assuming two different depreciation rates could be easily accommodated.
} 
familiar law of motion:

$$
k_{g a, t}=\left(1-\delta_{g}\right) k_{g a, t-1}+x_{g a, t} .
$$

Investment in both forms of public capital reacts to deviations of the corresponding capital stock from steady state according to the following rule:

$$
\log \left(\frac{x_{j, t}}{x_{j}}\right)=-\rho_{x j} \log \left(\frac{k_{j, t}}{k_{j}}\right)
$$

where $j=g, g a$. This feedback rule captures the reconstruction of public capital and, at the same time, accounts for the fact that replacing destroyed infrastructure entails additional spending that needs to be financed by either raising taxes or issuing new debt. Being immune to natural disasters, investment in resilient capital is needed only to replace depreciated capital. ${ }^{13}$ In some simulations (Section 6.2) we let donors finance a fraction $\vartheta \in[0,1]$ of the extra cost of investing in resilient capital, ı. Building resilient infrastructure entails employing better materials, more sophisticated technologies, better knowledge, etc., hence we assume that investment in resilient capital is more expensive than investment in standard infrastructure by a factor of $(1+\iota)$, thus bearing an additional cost, which weighs on public finances. We therefore capture a trade-off between building resilience and bearing higher costs, which makes the choice in favor of the former not obvious. ${ }^{14}$

To finance these expenditures, the government issues one-period bonds $b_{g, t}$ and mobilizes tax revenue $\tau_{t}^{c} c_{t}$ by taxing final good consumption at a rate $\tau_{t}^{c}$. In Section 6 , we explore also cases in which the government benefits from international aid in the form of post-disaster grants, $\phi$. Therefore the government budget constraint reads as follows:

$$
b_{g, t}=R_{t-1} b_{g, t-1}+g+x_{g, t}+[1+(1-\vartheta) \iota] x_{g a, t}-\tau_{t}^{c} c_{t}-\phi_{t} .
$$

The tax rate on consumption is set to react to deviations of public debt from the steady state according to parameter $\rho_{\tau b}$, while we account for gradual changes in the tax rate by setting a persistence parameter $\rho_{\tau}$ in the tax rule:

$$
\log \left(\frac{\tau_{t}^{c}}{\tau^{c}}\right)=\rho_{\tau} \log \left(\frac{\tau_{t-1}^{c}}{\tau^{c}}\right)+\rho_{\tau b} \log \left(\frac{b_{t}}{b}\right)
$$

\footnotetext{
${ }^{13}$ In addition to replacing the depreciated capital stock, investment in resilient capital adjusts also according to the stochastic growth rate of the economy. This specification abstracts from delays in the public investment process, e.g., time-to-build lags. Introducing such delays would exacerbate the negative macroeconomic effects of natural disasters.

${ }^{14}$ We implicitly assume perfect competition in the market for resilient capital therefore its price equals the marginal cost.
} 
Post-disaster grants can either accrue to the government from external donors in response to natural disasters. We therefore employ this simple feedback rule:

$$
\log \left(\frac{\phi_{t}}{\phi}\right)=\rho_{\phi} \log \left(\frac{\phi_{t-1}}{\phi}\right)+\left(1-\rho_{\phi}\right) \rho_{\phi d}\left(\frac{d_{t} \theta_{t}}{\bar{d} \bar{\theta}}\right)
$$

where $\rho_{\phi}$ governs the persistence of the disbursement of grants while $\rho_{\phi d}$ sets the sensitivity of grants to the magnitude of the natural disaster, thus determining the total amount disbursed.

Finally, for simplicity we assume that public debt is entirely external. Therefore one component of the real interest rate is determined in international financial markets and taken as given by the government. The other component is a sovereign risk premium determined by the percentage deviations of the stock of public debt from steady state:

$$
R_{t}=R e^{\eta\left(\frac{b_{g, t}}{b_{g}}-1\right)}
$$

where $\eta$ governs the elasticity of the interest rate paid on public debt. If $\eta=0$, as we assume in the baseline calibration, then the interest rate is constant. This modeling choice is justified by evidence suggesting that following a natural disaster, disaster-prone countries lose access to credit markets or see their financing costs skyrocket because their fiscal sustainability is at risk (see, e.g., S\&P, 2015, Marto et al., 2018 and Kling et al., 2018). Higher interest rates on public debt worsen the fiscal position further making the interest burden larger. This leads to a vicious cycle that leaves the disaster-prone country, on one hand, in need of spending

for reconstruction and, on the other hand, with more binding financing constraints making this spending more difficult.

\subsection{Market Clearing and the Balance of Payments}

In equilibrium all markets clear and the model is closed by the following identities:

$$
\begin{aligned}
y_{t} & =c_{t}+x_{t}+g+x_{g, t}+[1+(1-\vartheta) \iota] x_{g a, t}+n_{t}^{x}, \\
-\left(b_{g, t}-b_{g, t-1}\right) & =n_{t}^{x}+\phi_{t}-R_{t-1} b_{g, t-1},
\end{aligned}
$$

where equation (25) is the resource constraint, which features also net exports, $n_{t}^{x}$. Equation (26) is the balance of payments and defines the link between external public debt and the country's net exports. 


\section{Calibration and Solution Method}

We calibrate the model to an average country in the group of EMDEs at a quarterly frequency. To make meaningful comparisons, we assume that disaster and non-disaster-prone countries are perfectly symmetric except for the calibration of natural disaster shocks. Table 3 reports the choice of all parameter values for the baseline calibration.

Parameters Matching Data. We first set a number of parameters to match averages of macroeconomic aggregates over the past two decades (1998-2017) across all EMDEs. ${ }^{15}$ The ratio of public investment to GDP is calibrated at 7\%. The share of public capital in the total capital stock $\left(\alpha_{g}\right)$ is set such that (given the capital depreciation rates and the total capital share of income, $\alpha$, discussed below) the steady state ratio of private investment to GDP is $16 \%$, while The steady-state values of government consumption $(g)$ and the stock of public debt $\left(b_{g}\right)$ are calibrated to obtain the observed ratios to GDP of $16 \%$ and $58 \%$, respectively; ${ }^{16}$ while the tax rate $\left(\tau^{c}\right)$ is set such that the tax revenue amounts to the observed 15\% of GDP. Finally, net exports as a share of GDP display a trade deficit on average, therefore they are set to achieve $-12 \%$ of GDP in line with the data.

Parameters Taken from the Literature. Next, we take a set of parameters from the literature, mainly on developing economies. The leisure preference parameter $(\nu)$ is set such that agents work $1 / 3$ of their time, as conventional in the business cycle literature. The discount factor $(\beta)$ is set at 0.983 , such that it yields a steady-state annual (net) interest rate of $8.52 \%$ (or $2.13 \%$ quarterly), as reported by Garcia-Cicco et al. (2010) for a set of emerging market economies. Moreover, this value falls also in the range considered by Shen et al. (2018) for low-income countries. Trend TFP growth $\left(\Lambda_{A}\right)$ is set to 0.0035 , as suggested by Araujo et al. (2016) with reference to countries in the Economic and Monetary Community of Central Africa. We follow Garcia-Cicco et al. (2010) also in setting the total capital share of income $(\alpha)$ to 0.32 . The parameter governing investment adjustment costs $(\kappa)$ is set to 12 , in line with the calibration of Schubert and Turnovsky (2011) for a set of developing economies. Private and public capital depreciation rates ( $\delta$ and $\delta_{g}$, respectively) are borrowed from Shen et al. (2018) who assume that the latter is half of the former, at 0.025 and 0.0125 , respectively. The inverse of the intertemporal elasticity of substitution $(\hat{\Psi})$ is calibrated to the standard value of 0.5. ${ }^{17}$ Given the scant evidence on risk aversion within Epstein-Zin preferences

\footnotetext{
${ }^{15}$ We extract data from the World Development Indicators dataset maintained by the World Bank, except for the public debt, which we take from the IMF World Economic Outlook.

${ }^{16} \mathrm{GDP}$ is annualized when it appears in the denominator of the government debt-to-GDP ratio.

${ }^{17}$ This is in line with a large literature on both advanced and emerging and developing economies, see, e.g., Uribe and Yue (2006), Borensztein et al. (2017), Schmitt-Grohé and Uribe (2017; 2018), Gourio (2012),
} 
Table 3: Baseline Calibration.

Parameter

Value

Common parameters

Parameters matching data

Government investment to GDP

Share of standard public capital

Government consumption to GDP

Public debt to annual GDP

Steady-state consumption tax rate

Net exports to GDP

$\begin{array}{lr}\frac{\bar{x}_{g}}{y} & 0.0700 \\ \alpha_{g} & 0.2200 \\ \frac{g}{y} & 0.1600 \\ \frac{b}{4 y} & 0.5800 \\ \tau_{c} & 0.2100 \\ \frac{n^{x}}{y} & -0.1200\end{array}$

Parameters taken from the literature

Leisure preference parameter

Discount factor

Capital share of income

Total factor productivity trend growth rate

$\alpha$

0.0035

Investment adjustment costs

$\Lambda_{A}$

12.0000

Private capital depreciation rate

$\kappa$

0.0250

Public capital depreciation rate

Inverse intertemporal elasticity of substitution

0.0125

Risk aversion

0.5000

Persistence of total factor productivity

Standard deviation of total factor productivity shocks

$\delta$

3.8000

Persistence of tax rate

Persistence of disaster risk shocks

$\hat{\delta}$

0.5000

$\rho_{A}$

0.0250

$\sigma_{A}$

0.9000

$\rho_{\tau}$

0.9000

\section{Uncertain fiscal parameters}

Tax rate responsiveness to public debt

Standard public investment responsiveness

$\begin{array}{ll}\rho_{\tau_{b}} & 0.2250 \\ \rho_{x g} & 0.8000\end{array}$

\section{Disaster-prone countries}

Annual disaster probability

Mean disaster size

$p_{d} \quad 0.1620$

Standard deviation of disaster risk shocks

$\bar{\theta} \quad 0.0665$

$\sigma_{\theta} \quad 0.1270$

Non-disaster-prone countries

Annual disaster probability

Mean disaster size

$p_{d} \quad 0.0028$

Standard deviation of disaster risk shocks

$\bar{\theta} \quad 0.0052$

$\sigma_{\theta} \quad 0.0170$

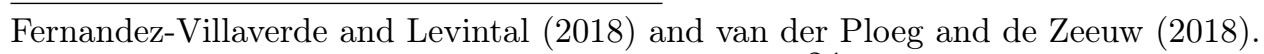


for developing economies, we set $\gamma=3.8$ as Gourio (2012) and Fernandez-Villaverde and Levintal (2018) do for the U.S. economy. ${ }^{18}$ Some experimental evidence in countries hit by natural disasters (Cassar et al., 2017 and Cameron and Shah, 2015) suggests that agents tend to exhibit a more risk averse behavior, although these findings are difficult to translate into a value of $\gamma \cdot{ }^{19}$ We therefore see the calibration of risk aversion based on the U.S. economy as a lower bound for disaster-prone countries. ${ }^{20}$ Schmitt-Grohé and Uribe (2017) report that the standard deviation and serial correlation of annual GDP in emerging economies are $8.71 \%$ and 0.87 , respectively. We therefore set the persistence $\left(\rho_{A}\right)$ and the standard deviation $\left(\sigma_{A}\right)$ of the TFP shock to match these moments at a quarterly frequency. We set the persistence of the tax rate $\left(\rho_{\tau}\right)$ to 0.90 , in line with the calibration of Shen et al. (2018) for low-income countries and close to the values estimated for the U.S. (i.e. Zubairy, 2014) and Euro Area economies (i.e. Coenen et al., 2013). ${ }^{21}$ Finally, absent evidence specific for EMDEs, we calibrate the persistence of the disaster risk shock $\left(\rho_{\theta}\right)$ to 0.90 in both type of countries, following Gourio (2012), Isoré and Szczerbowicz (2017) and Fernandez-Villaverde and Levintal (2018).

Uncertain Fiscal Parameters. The values of two fiscal parameters are uncertain. We then set the responsiveness parameter of the tax rate to public debt $\rho_{\tau b}=0.225$, which is approximately the minimum value that guarantees the stability of the model across all the exercises conducted. In Section 5.5 we perform robustness checks on this parameter along with others. Similarly, there is no empirical evidence available to calibrate the elasticity of public investment to the loss of public capital $\left(\rho_{x g}\right)$. Hence, we set it equal to 0.8, assuming less than a one-to-one reconstruction within the quarter, and then check how robust the baseline results are.

Disaster Shocks Parameters. In accordance with the evidence reported in Section 2, for disaster-prone countries we set the annual disaster probability $\left(p_{d}\right)$ to $16.2 \%$ and the average loss $(\bar{\theta})$ to $6.65 \%$ of GDP. The standard deviation $\left(\sigma_{\theta}\right)$ matches the quarterly dispersion of damages to GDP in disaster-prone countries of $28 \%$. As discussed, non-disaster-prone states are hit much less frequently and less severely by natural disasters, with an annual probability

\footnotetext{
${ }^{18}$ Values of risk aversion between 3 and 4 are needed to replicate the average equity premium, see Barro (2009; 2015) and Gourio (2012).

${ }^{19}$ See also van den Berg et al. (2009), Dang (2012) and Brown et al. (2018). Fiala (2017) reviews this evidence in more detail and reports also some contrasting results.

${ }^{20}$ Moreover, what is important for our analysis, as noted by Traeger (2014) and van der Ploeg and de Zeeuw (2018) in the context of climate change, is that we use a value of risk aversion larger than the inverse of the intertemporal elasticity of substitution to account for early resolution of uncertainty. This is consistent also with the empirical evidence on the U.S. provided by Vissing-Jorgensen and Attanasio (2003).

${ }^{21}$ This value is consistent also with Bi et al. (2016) who estimate a similar fiscal rule for Argentina.
} 
of $0.28 \%$, an average loss of $0.52 \%$ of GDP, and a quarterly dispersion of damages to GDP of $3.5 \%$.

Parameters Related to Additional Channels and policies. The remaining parameters governing how the sovereign risk premium $(\eta)$, resilient capital $\left(\psi_{g}, \rho_{x g a}, \iota\right)^{22}$ and inter-

national aid $\left(\frac{\phi}{y}, \rho_{\phi}, \rho_{\phi d}, \vartheta\right)$ enter the model are set to zero, essentially shutting down these channels and policies in the baseline results. Later on, we introduce these features one at a time in the model to disentangle their effects, and discuss the calibration of the relevant parameters in detail in the appropriate sections.

Solution Method. To simulate our model, we resort to Taylor projection, a new solution method proposed by Levintal (2018) and Fernandez-Villaverde and Levintal (2018) to solve DSGE models with rare disasters. Fernandez-Villaverde and Levintal (2018) demonstrate that a Taylor projection up to third order is more accurate and generally faster to compute than perturbation methods up to a fifth order of approximation and projection methods (Smolyak collocation) up to a third order to solve a wide range of DSGE models with rare disasters. ${ }^{23}$ Taylor projection essentially combines the setup of standard projection methods (e.g. Judd, 1992) with approximation methods via Taylor expansions. The method yields a solution that, although not global, is possible to approximate at many points of the statespace, and this makes it accurate in dealing with large nonlinearities. These features of Taylor projection are particularly appealing for studying natural disasters within a DSGE model and motivate our choice over alternative methods.

\section{The Macroeconomic Effects of Natural Disasters and Climate Change}

We now turn to simulating the effects of natural disasters and climate change in disasterprone developing countries to compare their macroeconomic outcomes and welfare to those of their non-disaster-prone peers. We first describe the dynamic responses of selected macroeconomic variables to a one-off natural disaster shock. Then, we look at the long-term effects of stochastic natural disaster shocks, occurring according to the calibrated frequency and magnitude.

\footnotetext{
${ }^{22} \psi_{g} \in[0,1]$ represents the stead-state share of resilient capital in the total public capital stock.

${ }^{23}$ In particular, Taylor projections perform much better than alternative methods both in terms of mean and maximum unit-free Euler errors across the ergodic set of the model. Mean and maximum unit-free Euler errors have been proposed by Judd (1992) to evaluate the accuracy of the model's solution.
} 
The exercises are performed as follows. As in Fernandez-Villaverde and Levintal (2018), we simulate the model calibrated to a disaster-prone country for 1000 periods (250 years) and compute the averages of selected macroeconomic variables, discarding the first 100 quarters. Next, we do the same for a non-disaster-prone country. Last, we compute the percentage difference between the simulation averages of the disaster-prone country relative to the nondisaster-prone country.

In addition to the long-run outcomes on the main macroeconomic aggregates, we also investigate how natural disasters weigh on the welfare of disaster-prone countries relative to non-disaster-prone ones, by measuring the welfare loss in consumption equivalent terms. From equation (1), let $\bar{V}^{\mathrm{NDP}}$ and $\bar{V}^{\mathrm{DP}}$ represent average welfare in non-disaster-prone and disaster-prone countries, respectively. Then, the welfare loss is implicitly defined by

$$
\bar{V}^{\mathrm{NDP}}\left\{(1-\omega) c_{t}^{\mathrm{NDP}}, l_{t}^{\mathrm{NDP}}\right\}=\bar{V}^{\mathrm{DP}}\left\{c_{t}^{\mathrm{DP}}, l_{t}^{\mathrm{DP}}\right\}
$$

where $\omega \times 100$ represents the percent permanent loss in consumption that should occur in non-disaster-prone countries in order for their households to be as well off as households in disaster-prone countries.

This welfare metric is standard in the literature of optimal monetary and fiscal policies (see e.g. Schmitt-Grohé and Uribe, 2007), but also comparable to some alternative welfare metrics used in the disasters literature. For instance, Barro (2009; 2015) computes the reduction in GDP (and in consumption, given that he studies endowment economies) that households are willing to suffer to completely eliminate the risk of disasters, i.e. by setting the probability of rare disasters equal to zero. ${ }^{24}$ Similarly, Donadelli et al. (2017) compute the loss in the optimal consumption path that agents are willing to suffer to completely eliminate long-term temperature risk. ${ }^{25}$

Given that our two representative countries differ only by the distributions of natural disaster shocks, our approach enables us to quantify how natural disasters (and in some

\footnotetext{
${ }^{24}$ While in Barro (2009) rare disasters do not include natural events, Barro (2015) extends the former model to include the probability of environmental disasters. However, he argues that no natural disasters occurred in the sample of countries considered (mainly advanced economies) hence he assumes a $1 \%$ annual probability of natural disaster, which adds to the annual probability of non-environmental rare disasters (e.g. wars and financial crises).

${ }^{25}$ Therefore, our welfare results are qualitatively and quantitatively comparable to this strand of the DSGE literature more than to studies employing Integrated Assessment Models (IAMs), such as Cai et al. (2017). In fact, these studies usually measure welfare effects of carbon emissions by the Social Cost of Carbon (SCC), that is the marginal economic loss in US\$ caused by an extra metric ton of atmospheric carbon. Popular IAMs are DICE (Nordhaus, 1992), FUND (Anthoff and Tol, 2014) and PAGE (Hope, 2011). The SCC then determines the Pigouvian carbon tax needed to address the negative externality caused by emissions. Tol (2009) reviews the welfare effects of the literature by calculating permanent losses in GDP. Despite large differences in the models and welfare metrics, we qualitatively relate our welfare results also to Cai et al. (2017) and studies reviewed by Tol (2009).
} 
exercises, shifts in their distributions that may be caused by climate change) weigh on the macroeconomic performance and welfare of disaster-prone countries compared to their nondisaster-prone peers.

\subsection{The Effects of a One-Off Natural Disaster}

Figure 4 shows the impulse responses of selected macroeconomic variables to a one-off natural disaster in the representative disaster-prone country. All responses are in percentage deviations from the stochastic steady state and include the trend component, except for the tax rate and the ratio of public debt to annual GDP for which we report the absolute changes in percentage terms. In response to a natural disaster that destroys $6.65 \%$ of GDP on impact, consumption and public investment fall by about $6 \%$. Private investment falls only marginally on impact and it overshoots to replace the lost capital, driving the recovery. Public debt to GDP increases by 3.5 percentage points on impact and then gradually decreases thanks to the increase in the tax rate. ${ }^{26}$ The figure also highlights persistent effects of a natural disaster on the economy, which takes about three years to fully recover. It is worth stressing, however, that this exercise takes only a one-off event of average intensity into account. Some disaster-prone countries are frequently hit by natural disasters, such that they may not fully recover from a disaster shock before another shock occurs. The effects of sequences of shocks accumulate over time weighing permanently on macroeconomic outcome. We quantify these effects in Subsection 5.2.

Disaster-prone countries may also suffer from extreme events, as shown in Table B.1 of Appendix B, where we report the 20 most damaging natural disasters in our sample. As an illustration, we investigate the response of macroeconomic variables to a natural disaster shock of the same intensity as Hurricane Matthew, which tragically hit Haiti on October 4, 2016 as a Category 4 hurricane. ${ }^{27}$ By causing damages of $25 \%$ of GDP in Haiti, Hurricane Matthew places itself in the middle of the list of the 20 most damaging natural disasters, and the country has not yet recovered from the event. ${ }^{28}$

\footnotetext{
${ }^{26}$ The increase in the tax rate is necessary to prevent public debt from exploding and to ensure the stability of the model's solution. Absent the possibility for the government to increase taxes (or cut expenditures) or for international aid to sustain the government's budget, the economy may face sovereign debt sustainability challenges.

${ }^{27}$ Hurricanes are classified in five categories according to the Saffir-Simpson Hurricane Wind Scale and the resulting types of damages (more details can be retrieved from the National Hurricane Center website, link here), where Category 5 includes the most powerful hurricanes. According to the Saffir-Simpson Hurricane Wind scale, a Category 4 hurricane causes catastrophic damages: "well-built framed homes can sustain severe damage with loss of most of the roof structure and/or some exterior walls. Most trees will be snapped or uprooted and power poles downed. Fallen trees and power poles will isolate residential areas. Power outages will last weeks to possibly months. Most of the area will be uninhabitable for weeks or months."

${ }^{28}$ As reported by the World Bank (link here) and ReliefWeb (a specialized digital service of the UN Office for
} 
Figure 4: Impulse Responses of Selected Macroeconomic Variables to an Average Natural Disaster Shock in a Disaster-Prone Country.
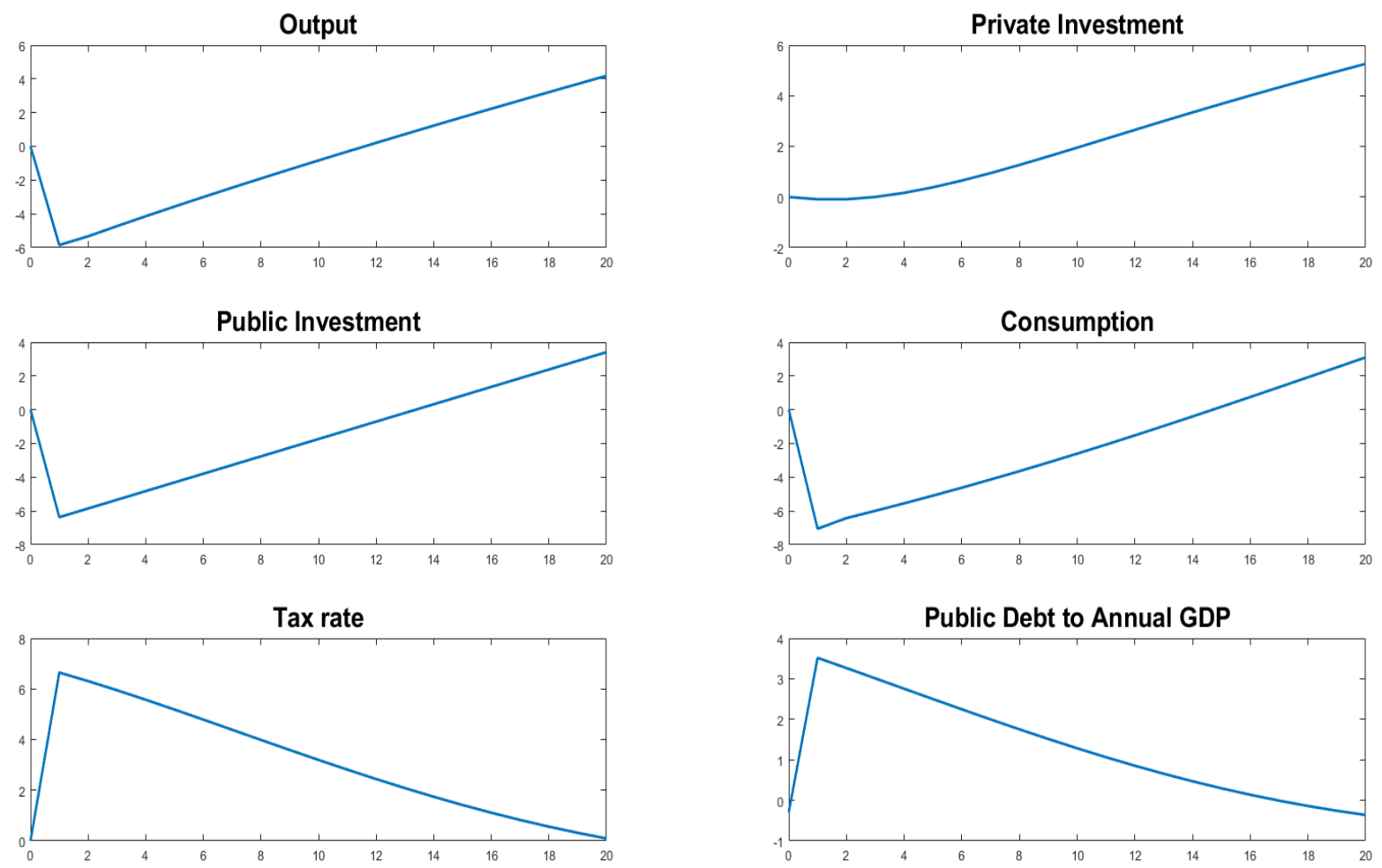

Notes: X-axes are in quarters. Y-axes are in percent deviations from the stochastic steady state, with the exception of the tax rate and public debt to annual GDP, which are absolute changes in percentage terms. The stochastic steady state is obtained by simulating the model in the absence of shocks for 100 quarters.

Figure 5 shows the impulse responses to a one-off natural disaster shock of the same intensity as Hurricane Matthew in Haiti (dashed red lines), which is almost four times larger than the average event in disaster-prone countries (bold blue lines). The effects of such a shock are not only remarkably larger, but also much more persistent relative to the average disaster. Five years after the shock, GDP, consumption and both public and private investment are still far away from pre-disaster levels. Differently from the case of an average disaster, simulations (not shown in the figure) imply that it takes 15 years for private investment to get back to the stochastic steady state. Therefore the non-linear solution method allows capturing the impact that the intensity of the shock has on the persistence of the macroeconomic effects. This aspect could not have been captured by a linearized model.

the Coordination of Humanitarian Affairs (OCHA), link here), "the hurricane brought extensive flooding and mudslides, damages to road infrastructure and buildings, electrical grid and the water system; additionally, the hurricane impacted telecommunications in the affected areas due to the lack of electrical power and damages to both the electrical and telecommunication grids. Up to 90 percent of crops and livestock were lost in some areas and thousands of structures were damaged, and key roads and bridges were washed away. The disaster affected over 2 million people, about 20 percent of Haiti's population, with 546 deaths reported". 
Figure 5: Impulse Responses of Selected Macroeconomic Variables to a Natural Disaster Shock of the Same Intensity as Hurricane Matthew Hitting Haiti in 2016.
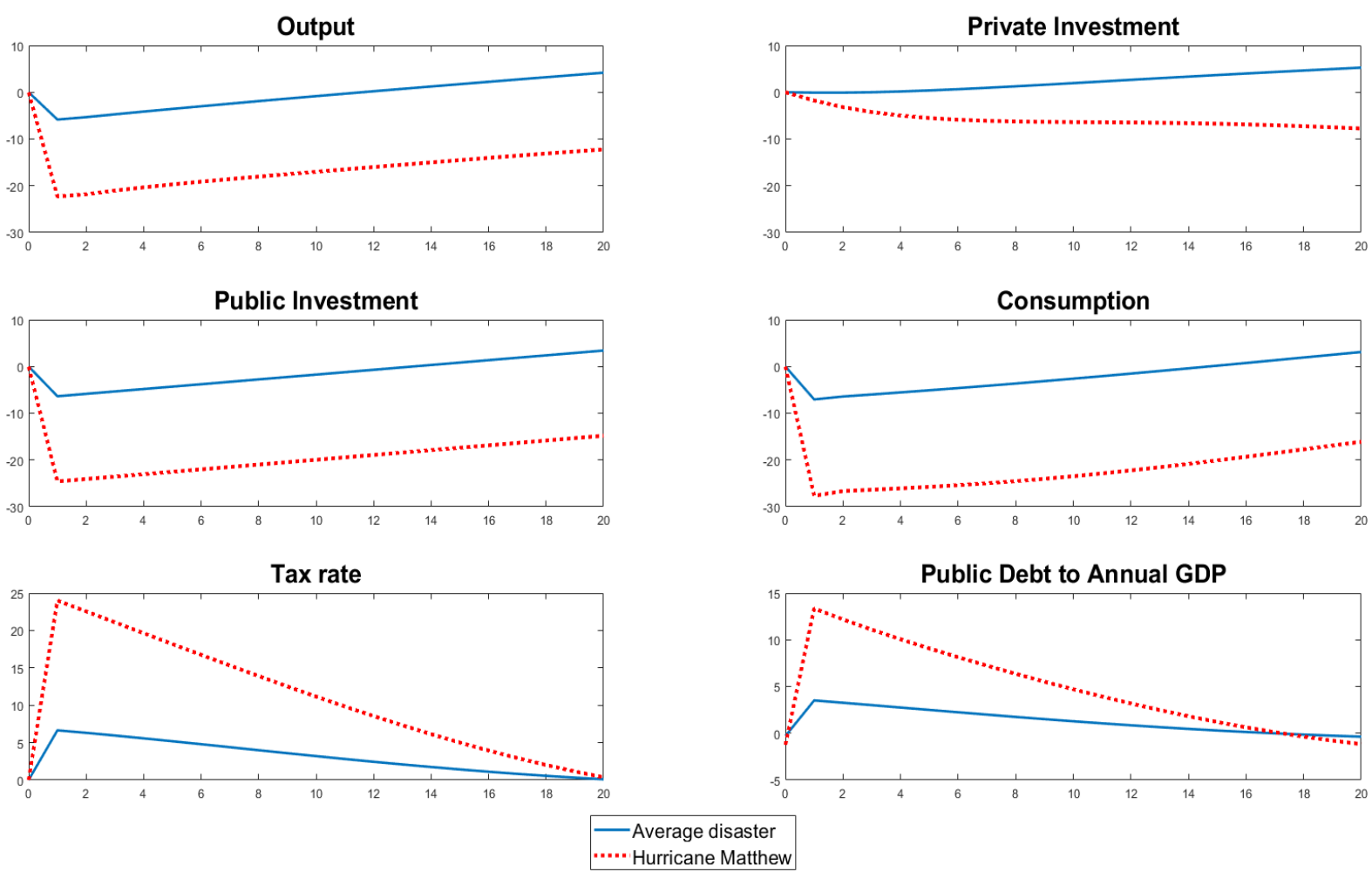

Notes: X-axes are in quarters. Y-axes are in percent deviations from the stochastic steady state, with the exception of the tax rate and public debt to annual GDP, which are absolute changes in percentage terms. The stochastic steady state is obtained by simulating the model in the absence of shocks for 100 quarters. Bold blue lines represents an average natural disaster shock in a disaster-prone country. Dashed red lines represents a natural disaster shock of the same intensity as Hurricane Matthew hitting Haiti in 2016.

\subsection{The Long-Run Effects of Natural Disasters}

Table 4 reports the percentage difference in the long-run simulation averages of macroeconomic aggregates in disaster-prone countries relative to non-disaster-prone countries, along with the implied welfare loss. These differences therefore quantify the long-run adverse effects that disaster-prone countries suffer exclusively because of more frequent and powerful natural disasters.

Simulation results suggest large and permanent effects. The top panel of Table 4 shows that, in disaster-prone countries, average annual GDP growth is almost 1\% lower than in non-disaster-prone countries, suggesting a sizable divergence of the GDP paths of the two groups of countries entirely due to their different exposure to natural disasters. ${ }^{29}$ Moreover, disaster-prone countries exhibit a public debt level on average 1.54 percentage points of

\footnotetext{
${ }^{29}$ Absent policy interventions or other compensatory mechanisms.
} 
Table 4: Average Effects of Natural Disaster Shocks in Disaster-Prone Countries.

\begin{tabular}{lc}
\hline & $\begin{array}{c}\text { Simulation average } \\
\text { (differences relative to }\end{array}$ \\
& non-disaster-prone countries) \\
\hline GDP growth (annual) & -0.96 \\
Public debt (\% of annual GDP) & 1.54 \\
& \\
Cyclical components (\% differences) & \\
GDP & -0.29 \\
Consumption & -0.89 \\
Private Investment & -1.28 \\
& \\
Divergence over 30 years (\% differences) & \\
GDP & -37.9 \\
Consumption & -39.4 \\
Private Investment & -37.3 \\
\hline & Consumption equivalent $(\omega \times 100)$ \\
Welfare loss & 1.59 \\
\hline
\end{tabular}

Notes: Simulation averages are obtained by simulating the model for 1000 quarters with a burn-in of 100 quarters. Simulation averages for disaster-prone countries are reported in percent differences relative to non-disaster-prone countries, with the exception of GDP growth and public debt to annual GDP, for which we report absolute changes in percentage terms. Divergence over 30 years is calculated by using the value of the simulated variables 120 quarters after the stochastic steady state. The stochastic steady state is obtained by simulating the model in the absence of shocks for 100 quarters. Welfare loss is expressed in consumption equivalent terms, i.e. how much consumption households in a non-disaster-prone country must permanently give up in order to reach the same welfare as households in disaster-prone countries.

annual GDP higher than in non-disaster-prone countries.

Natural disaster shocks in the model affect both the trend and the cyclical components of macroeconomic aggregates. The second panel of Table 4 disentangle the effects on the cyclical components of GDP, private consumption and private investment. On average, the losses in the cyclical components of GDP, private consumption and investment are $0.29 \%$, $0.89 \%$ and $1.28 \%$, respectively.

Turning to the level effects of natural disasters, the third panel of Table 4 reports the differences in the levels of GDP, private consumption and private investment of disasterprone countries relative to non-disaster-prone countries over 30 years. The 30-year levels for each country group are calculated by simulating the variables for 120 quarters starting from the stochastic steady state, and by normalizing the two time series such that they have the same value in the initial quarter. Consistently with the permanently lower growth result, after 30 years GDP, private consumption and private investment are almost $40 \%$ lower in disaster-prone countries relative to their non-disaster-prone peers. 
Finally, we turn to computing welfare losses. Households in disaster-prone countries, simply from being exposed to more frequent and powerful weather disasters, suffer a welfare loss equivalent to a permanent reduction in consumption of $1.59 \%$. While these welfare losses are orders of magnitude larger than losses reported in standard models of optimal monetary and fiscal policies (e.g. Schmitt-Grohé and Uribe, 2007), they are in line with those computed in models with rare disasters and temperature shocks. ${ }^{30}$ In particular, Barro (2009) calculates welfare losses of about 8-9\% arising from the risk of rare disasters (not necessarily natural disasters). Similarly, Donadelli et al. (2017) report welfare losses of 4.6\% and $9.2 \%$ due to the long-run temperature risk, depending on the elasticity of productivity to temperature shocks. ${ }^{31}$ Our welfare loss, despite being of the same order of magnitude, is lower because we calculate it relative to a calibration with less frequent and less damaging natural disasters. Conversely, both Barro (2009) and Donadelli et al. (2017) compute the welfare losses relative to a scenario where rare disasters and temperature shocks are completely eliminated. Moreover, relative to Barro (2009), in line with our stylized facts, we assume a larger disaster probability (16.2\% vs $1.7 \%$ ) but our average damage is almost 4 times smaller (6.65\% vs $26 \%$ of GDP).

Within the Intergrated Assessment Model (IAM) literature, Cai et al. (2017) calculate a Social Cost of Carbon (SCC) between $\$ 40-\$ 100$, depending on the parametrization of the model. Importantly, they show that the SCC is increasing in uncertainty over irreversible climate change. This implies that not only actual events, but also the risk of their realization affect agent's choices and policy responses, in similar fashion to what happens in our model. Moreover, Tol (2009) calculates that in Nordhaus and Yang (1996), who apply a regional version of the Dynamic Integrated Climate-Economy model (DICE, Nordhaus, 1992), a 2\% loss is suffered in developing countries from climate change, which is of the same order of magnitude as ours.

All in all, a rather dramatic picture emerges from these results. Disaster-prone countries experience a widening income gap relative to their non-disaster-prone peers, a worse fiscal position characterized by a higher level of public debt, and lower welfare.

\footnotetext{
${ }^{30}$ Tallarini Jr. (2000) shows that with EZ preferences welfare losses are orders of magnitudes larger than in models with standard expected utility, which is one determinant of the difference. The remainder is explained by the presence of large shocks and nonlinearities.

${ }^{31}$ Both Barro (2009) and Donadelli et al. (2017) calibrate their models at an annual frequency, while we study a quarterly model. For the purpose of comparison, we have converted their welfare losses from annual to quarterly.
} 


\subsection{The Effects of Climate Change}

We now turn to examine the effects of climate change. In our model climate change manifests itself into a shift in the distribution of natural disasters, making these events more frequent and more powerful (IPCC, 2014). Despite some attempts to estimate the increase in the probability of catastrophic events (see e.g. IMF, 2017 and references therein), there is no systematic projection of hazard rates and damages available (to the best of our knowledge). Therefore, to simulate climate change scenarios, we apply the percentage increase in average probability and damages occurred in disaster-prone countries from the early decade of our sample (1998-2007) to the most recent decade (2008-2017), as reported in Tables 1 and 2. In other words we assume that, because of climate change, the annual probability of a natural disaster increases by $35 \%$ (from $16.2 \%$ to $21.9 \%$ ), while damages per disaster increase by $82 \%$ (from $6.65 \%$ to $12.1 \%$ of GDP).

Table 5 summarizes the results. The second column reports the baseline results (borrowed from Table 4), while the third to fifth columns report the percentage differences in the averages of macroeconomic variables relative to non-disaster-prone countries under three scenarios simulating climate change. In the first, we allow only the frequency of natural hazards to increase; in the second we augment only their average impact; in the third both the frequency and magnitude of natural disasters increase.

Results reveal a dramatic deterioration of the relative macroeconomic performance of disaster-prone countries. Annual GDP growth is impaired, especially due to larger damages per disaster. When the effects of higher frequency and magnitude are combined, on average disaster-prone countries grow at an annual rate $2.66 \%$ lower than non-disaster-prone countries, and exhibit a public debt level as higher as 11.2 percent of GDP. Likewise, there are magnified effects on the business cycle components of GDP, consumption and private investment. It is also worth stressing that these effects have the potential to trigger a serious divergence process of disaster-prone countries, with the level of their GDP being 115\% lower than in non-disaster-prone countries after 30 years. Finally, climate change may multiply consumption-equivalent welfare losses of disaster-prone countries by a factor of seven.

\subsection{An Amplifier: The Sovereign Risk Premium}

We now turn to study an amplifier of the effects of natural disasters: the sovereign risk premium. The interest in this amplifier arises from the observation that, as countries are hit by extreme weather events, they typically face higher borrowing costs or, in the limit, they may even lose access to international financial markets. According to Standard \& Poor's (2015), countries hit by weather-related events may face a downgrade of their sovereign debt 
Table 5: Average Effects of Climate Change in Disaster-Prone Countries.

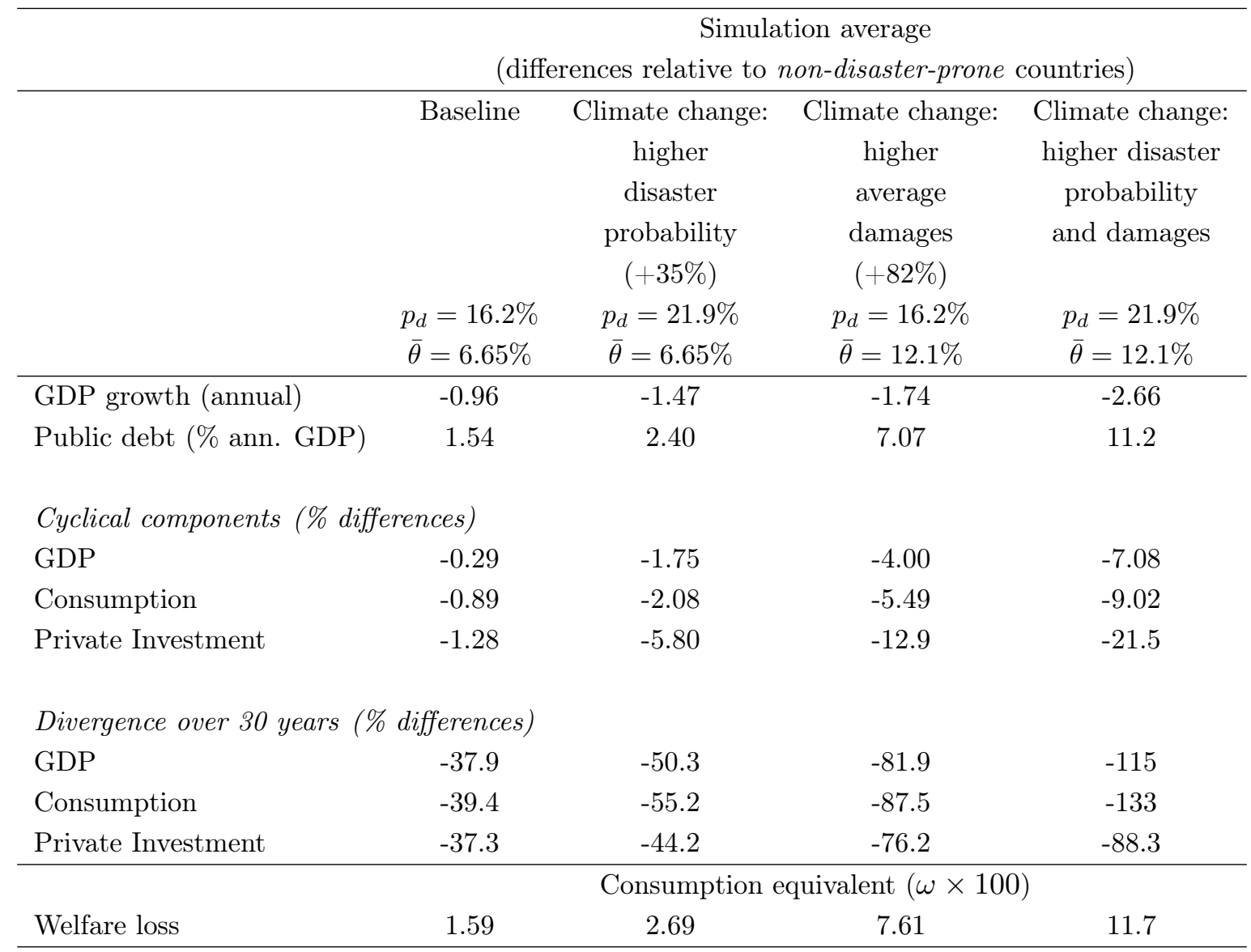

Notes: Simulation averages are obtained by simulating the model for 1000 quarters with a burn-in of 100 quarters. Simulation averages for disaster-prone countries are reported in percent differences relative to non-disaster-prone countries, with the exception of GDP growth and public debt to annual GDP, for which we report absolute changes in percentage terms. Divergence over 30 years is calculated by using the value of the simulated variables 120 quarters after the stochastic steady state. The stochastic steady state is obtained by simulating the model in the absence of shocks for 100 quarters. Welfare loss is expressed in consumption equivalent terms, i.e. how much consumption households in a non-disaster-prone country must permanently give up in order to reach the same welfare as households in disaster-prone countries.

between 1.5 and 2.5 notches. While notches of change in sovereign creditworthiness cannot be linearly translated into changes in interest rates, Marto et al. (2018), e.g., assume that a 1.5 notches downgrade implied a $15 \%$ increase in the interest paid by the government of Vanuatu following Cyclone Pam in 2015. Kling et al. (2018) estimate that countries vulnerable to natural disasters pay, on average, a $1.17 \%$ higher cost of debt relative to countries less exposed to climatic events.

Given the large uncertainty and the scant literature surrounding the effects of natural disasters on sovereign debt, we take the following approach. We consider a representative disaster-prone country with a relatively developed financial market: Jamaica. Then, we 
Table 6: Additional Effects of the Sovereign Risk Premium in Disaster-Prone Countries.

Simulation average

(differences relative to non-disaster-prone countries)

\begin{tabular}{|c|c|c|c|c|}
\hline & $\begin{array}{c}\text { Baseline } \\
\begin{array}{c}p_{d}=16.2 \% \\
\bar{\theta}=6.65 \% \\
\eta=0\end{array}\end{array}$ & $\begin{array}{c}\text { Sovereign } \\
\text { risk premium } \\
\begin{array}{c}p_{d}=16.2 \% \\
\bar{\theta}=6.65 \% \\
\eta=0.01\end{array}\end{array}$ & $\begin{array}{l}\text { Climate change } \\
\begin{array}{c}\text { alone } \\
p_{d}=21.9 \% \\
\bar{\theta}=12.1 \% \\
\eta=0\end{array}\end{array}$ & $\begin{array}{c}\text { Climate change }+ \\
\text { sovereign risk premium } \\
\begin{array}{c}p_{d}=21.9 \% \\
\bar{\theta}=12.1 \% \\
\eta=0.01\end{array}\end{array}$ \\
\hline GDP growth (annual) & -0.96 & -0.96 & -2.66 & -2.66 \\
\hline Public debt (\% ann. GDP) & 1.54 & 2.51 & 11.2 & 14.6 \\
\hline \multicolumn{5}{|c|}{ Cyclical components (\% differences) } \\
\hline GDP & -0.29 & -0.44 & -7.08 & -7.74 \\
\hline Consumption & -0.89 & -1.39 & -9.02 & -10.7 \\
\hline Private Investment & -1.28 & -1.50 & -21.5 & -21.4 \\
\hline \multicolumn{5}{|c|}{ Divergence over 30 years ( $\%$ differences) } \\
\hline GDP & -37.9 & -38.0 & -115 & -117 \\
\hline Consumption & -39.4 & -40.3 & -133 & -137 \\
\hline \multirow[t]{2}{*}{ Private Investment } & -37.3 & -35.8 & -88.3 & -81.9 \\
\hline & \multicolumn{4}{|c|}{ Consumption equivalent $(\omega \times 100)$} \\
\hline Welfare loss & 1.59 & 2.69 & 11.7 & 14.5 \\
\hline
\end{tabular}

Notes: Simulation averages are obtained by simulating the model for 1000 quarters with a burn-in of 100 quarters. Simulation averages for disaster-prone countries are reported in percent differences relative to non-disaster-prone countries, with the exception of GDP growth and public debt to annual GDP, for which we report absolute changes in percentage terms. Divergence over 30 years is calculated by using the value of the simulated variables 120 quarters after the stochastic steady state. The stochastic steady state is obtained by simulating the model in the absence of shocks for 100 quarters. Welfare loss is expressed in consumption equivalent terms, i.e. how much consumption households in a non-disaster-prone country must permanently give up in order to reach the same welfare as households in disaster-prone countries.

compute the average change in the interest rate on Jamaica's Treasury Bills in the month of each natural disaster occurred between 1998 and 2017. ${ }^{32}$ It turns out that, on average, in the months in which natural disasters occurred in Jamaica, the interest rate paid on public debt increased by $3.15 \%$. We therefore match this interest rate increase, within the calibration of the disaster-prone country, by setting $\eta=0.01$.

We first isolate the amplification effect of the sovereign risk premium relative to the baseline calibration, and then introduce it into the climate change scenario designed in Section 5.3 , where both the probability and magnitude of natural disasters increase. Table 6 shows

\footnotetext{
${ }^{32}$ Data on Jamaica's Treasury Bills interest rates at monthly frequency are available in the Government Finance Statistics database (GFS) maintained by the IMF. Formally estimating the effects of natural disasters on government bonds yields is beyond the scope of the paper and is left for future research.
} 
that the sovereign risk premium does not have a material role on GDP growth on average, while it further weighs on public debt by almost 1 percentage point of annual GDP, and on welfare. In general, the sovereign risk premium delivers small effects in the baseline scenario. It manifests itself more (and in a non-linear fashion) on the cyclical fluctuations of the macroeconomic variables, on public debt, and on welfare in the climate change scenario. In this case, the effect on public debt is sizable, as it amounts to an additional $3.4 \%$ of annual GDP. Given that the government has to raise taxes to prevent debt from taking an explosive path, private consumption is lower, reducing welfare further. The combination of climate change and sovereign risk premium brings welfare losses to $14.5 \%$ in consumption-equivalent terms, more than nine times the welfare losses suffered in the baseline scenario.

\subsection{Robustness Checks}

In this subsection we check whether our main results are robust to different parametrizations, including of the uncertain fiscal parameters described in Section 4. The first column of Table 7 report the baseline results while columns 2-7 reports the robustness checks. Overall, we find that our conclusions continue to hold under the alternative calibrations explored. We generally find mild differences relative to the baseline results (with some exceptions in public debt and welfare) due to the fact that we change the calibration for both the disaster- and non-disaster-prone countries but we keep the distribution of the shocks as in the baseline. It is noteworthy that the alternative calibrations affect the differences in GDP growth only at the third decimal digit. This is due to the fact that the stochastic trend growth of the economy is affected by TFP, which in turn is affected by the realizations of natural disasters. In the robustness checks we keep the distribution of the shocks as in the baseline scenario, leaving the trend growth of the economy unchanged.

Tax Rule. We first change the parameters of the tax rule (22) by alternatively increasing the reaction to deviations of public debt from the steady state and by lowering its persistence. The baseline calibration of the reaction parameter $\left(\rho_{\tau b}=0.225\right)$ is the lowest that guarantees the stability of the model. We therefore check how our results are affected by increasing it to 0.30 . Column 2 of Table 7 shows that while the increase in public debt is mitigated, a higher reaction to public debt has no material effect on the rest of the results, with differences in the simulation averages and welfare loss of disaster-prone relative to non-disaster-prone countries of the same order of magnitude as the baseline. Next, we reduce the persistence of the changes in the tax rate in reaction to public debt to $\rho_{\tau}=0.85$ from the value of 
Table 7: Robustness Checks.

\begin{tabular}{|c|c|c|c|c|c|c|c|}
\hline & \multicolumn{7}{|c|}{$\begin{array}{l}\text { Simulation average } \\
\text { (differences relative to non-disaster-prone countries) }\end{array}$} \\
\hline & $(1)$ & (2) & (3) & (4) & $(5)$ & $(6)$ & (7) \\
\hline & Baseline & \multicolumn{2}{|c|}{ Fiscal rule } & \multirow{2}{*}{\multicolumn{2}{|c|}{$\begin{array}{l}\text { Public investment } \\
\text { reaction }\end{array}$}} & Public capital & Lower disaster \\
\hline & & Higher & Lower & & & depreciation rate & risk persistence \\
\hline & & reaction & persistence & Lower & Higher & & \\
\hline & & $\rho_{\tau b}=0.30$ & $\rho_{\tau}=0.85$ & $\rho_{x g}=0.60$ & $\rho_{x g}=1.00$ & $\delta_{g}=0.025$ & $\rho_{\theta}=0.50$ \\
\hline GDP growth (annual) & -0.96 & -0.96 & -0.96 & -0.96 & -0.96 & -0.96 & -0.96 \\
\hline Public debt ( $\%$ ann. GDP) & 1.54 & 0.91 & 3.81 & 1.53 & 1.53 & 1.56 & 0.94 \\
\hline \multicolumn{8}{|c|}{ Cyclical components (\% differences) } \\
\hline GDP & -0.29 & -0.19 & -0.44 & -0.29 & -0.30 & -0.32 & -0.27 \\
\hline Consumption & -0.89 & -0.76 & -1.29 & -0.89 & -0.89 & -0.92 & -0.62 \\
\hline Private Investment & -1.28 & -1.35 & -1.06 & -1.28 & -1.28 & -1.27 & -1.28 \\
\hline \multicolumn{8}{|c|}{ Divergence over 30 years (\% differences) } \\
\hline GDP & -37.9 & -37.5 & -38.6 & -37.9 & -37.8 & -37.9 & -42.3 \\
\hline Consumption & -39.4 & -39.5 & -38.8 & -39.4 & -39.4 & -39.3 & -41.9 \\
\hline \multirow[t]{2}{*}{ Private Investment } & -37.3 & -36.3 & -38.9 & -37.3 & -37.2 & -37.5 & -44.1 \\
\hline & \multicolumn{7}{|c|}{ Consumption equivalent $(\omega \times 100)$} \\
\hline Welfare loss & 1.59 & 1.34 & 2.49 & 1.59 & 1.59 & 1.63 & 1.15 \\
\hline
\end{tabular}

Notes: Simulation averages are obtained by simulating the model for 1000 quarters with a burn-in of 100 quarters. Simulation averages for disasterprone countries are reported in percent differences relative to non-disaster-prone countries, with the exception of GDP growth and public debt to annual GDP, for which we report absolute changes in percentage terms. Divergence over 30 years is calculated by using the value of the simulated variables 120 quarters after the stochastic steady state. The stochastic steady state is obtained by simulating the model in the absence of shocks for 100 quarters. Welfare loss is expressed in consumption equivalent terms, i.e. how much consumption households in a non-disaster-prone country must permanently give up in order to reach the same welfare as households in disaster-prone countries. Averages in GDP growth differ at the third decimal digit. 
0.90 assumed in the baseline. ${ }^{33}$ Column 3 of Table 7 suggests that macroeconomic outcomes and welfare would be worse than the baseline, especially as regards public debt, the increase of which is more than twice than in the baseline calibration. Overall, however, the main implications of our baseline results continue to hold under these alternative calibrations of the fiscal rule.

Public Investment Rule. Parameter $\rho_{x g}$ governs the reaction of investment in public infrastructure to deviations of the capital stock from its steady state and captures how much of the public capital destroyed by natural disasters is reconstructed within the period. Our baseline calibration assumes that $\rho_{x g}=0.80$, thus a partial reconstruction. As a robustness, we either assume less or full reconstruction, by setting $\rho_{x g}=0.60$ or $\rho_{x g}=1$, respectively. Columns 5 and 6 of Table 7 show that our results are virtually immune to these changes.

Depreciation Rate of Public Capital. We next check whether doubling the depreciation rate of public capital $\delta_{g}$ from 0.0125 to 0.025 significantly affects the results. This essentially makes public capital depreciate at the same rate as private capital. Column 6 of Table 7 suggest only slight differences relative to the baseline results, with mild increases in public debt and welfare which nevertheless leave our conclusions unaltered.

Persistence of the disaster risk shock. In the baseline calibration we set the persistence of the disaster risk shock $\left(\rho_{\theta}\right)$ to 0.90, following Gourio (2012), Isoré and Szczerbowicz (2017) and Fernandez-Villaverde and Levintal (2018). We then lower this parameter to 0.50 and find that there is only a mild improvement in welfare and a lower increase in public debt relative to the baseline calibration (see Column 7 of Table 7). This is essentially due to the fact that agents expect that once a natural disaster hits, its effects will be shorter lived than what they expect according to our baseline calibration.

\section{$6 \quad$ Policy Responses}

In this section we assess the role of ex-post (post-disaster) and ex-ante (pre-disaster) policies in mitigating the effects of natural disasters on the welfare of disaster-prone countries. In Subsection 6.1 we study ex-post interventions that take the form of grants disbursed by external donors in the aftermath of natural disasters. In Subsection 6.2 we assess an $e x$ ante policy, whereby the government invests in resilient public infrastructure financed either

\footnotetext{
${ }^{33}$ We could only slightly reduce the parameter to preserve the stability of the model, keeping the same value of the reaction parameter $\rho_{\tau b}$.
} 
entirely using domestic resources or partly by international donors. ${ }^{34}$ The focus on the welfare effects of the policy responses is conventional in the macroeconomic literature on climate change. For instance, although with reference to mitigation policies reducing emissions, Nordhaus (2019) notes that an appropriate policy response is the one that preserves living standards, and thus welfare, in poor nations.

\subsection{Ex-Post International Aid}

In this scenario the government receives external grants from international donors whenever the country is hit by a natural disaster, according to rule (23). Figure 6 reports welfare gains in disaster-prone countries as a function of (a) the amount of grants received (governed by the reaction parameter $\rho_{\phi d}$ ), and (b) the extent to which a fixed amount of grant is spread out over time (obtained by changing the persistence parameter $\rho_{\phi}$, for a given $\rho_{\phi d}$ ).

In particular, Panel (a) of Figure 6 shows welfare gains (in percent of the baseline welfare loss, i.e. $\omega \times 100=1.59$ ) as a function of yearly average grants expressed as a share of GDP. ${ }^{35}$ As expected, higher grants monotonically improve welfare in disaster-prone countries. Interestingly, a sufficiently strong contribution of donors $\left(\rho_{\phi d}=35\right)$ might be able to eliminate the welfare losses suffered by disaster-prone countries due to weather-related shocks. This implies that the average yearly grant should amount to $2.6 \%$ of annual GDP. Taking the average GDP (in constant 2010 USD) in the group of disaster-prone countries (which roughly corresponds to the GDP of Haiti), this corresponds to 206 millions of US dollars every year, ${ }^{36}$ a grant amount that by far outweighs the amount typically received by countries hit by natural disasters.

To put things in perspective, in response to Hurricane Matthew, the Haitian government called for international humanitarian assistance and a Post-Disaster Needs Assessment (PDNA) was undertaken under the leadership of the Haitian Ministry of Planning, with support from the World Bank Group, the European Union, the Inter-American Development Bank, UNDP and various UN agencies. In November 18, 2016, the IMF mobilized 41.6 millions of US dollars under their Rapid Credit Facility (RCF, link here) to sustain the

\footnotetext{
${ }^{34}$ These exercises show the effects of ex-ante versus ex-post intervention, assumed to be conducted in the same way in all types of countries. Policy responses are often tailored to the country-specific distribution of natural hazards, e.g., rare but more powerful events might require issuance of catastrophe bonds (Borensztein et al., 2017), whereas more frequent disasters might ask for building more structural resilience. The IMF and World Bank conduct a Climate Change Policy Assessment (CCPA, see IMF 2016, 2019b) in disaster-prone countries, whereby natural disaster risks are integrated into the macro-fiscal framework. As part of the CCPA fiscal policies for mitigation, resilience building resilience, insurance and risk-pooling schemes are evaluated and recommended.

${ }^{35}$ We translate the amount of grants disbursed in the aftermath of the disasters into an yearly average to make it comparable to the grants that finance resilient investment in Section 6.2.

${ }^{36}$ We use GDP in constant 2010 USD from the World Bank's WDI database.
} 
Figure 6: Welfare Effects of Grants in Disaster-Prone Countries.

(a) Welfare Effects of Different Amounts of Grants

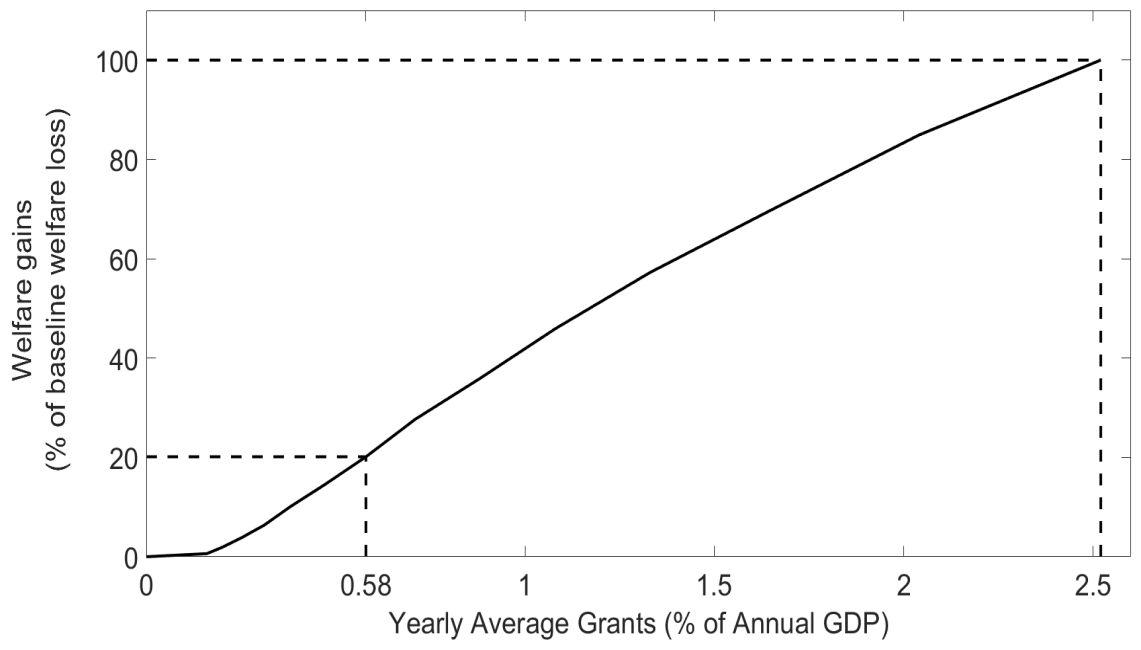

(b) Welfare Effects of the Dynamics of Grants Disbursement For a Given Grant Amount (0.58\% of Annual GDP)

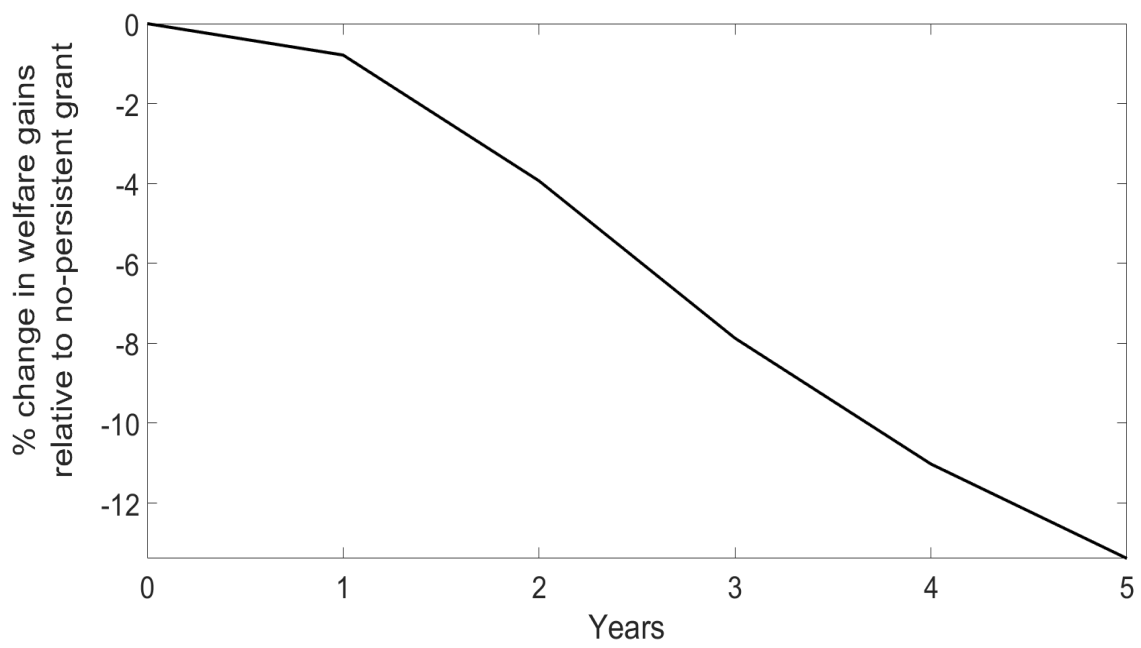

Notes: In Panel (a) amounts of grants as a \% of GDP are obtained by changing the reaction parameter $\rho_{\phi d} \in[0,35]$; in Panel (b) the number of years within which a yearly grant of $0.58 \%$ of GDP is disbursed is obtained by changing the persistence parameter $\rho_{\phi} \in[0,0.50]$. Welfare gains in Panel (a) are calculated as the percentage difference between the welfare loss in the baseline simulations and the welfare losses under different amounts of grants. Welfare gains in panel (b) are calculated as the percentage difference between the welfare loss with a yearly grant of $0.58 \%$ of GDP disbursed entirely at the time of the disaster (no persistence) and the welfare losses suffered under different time horizons within which the grant is disbursed.

reconstruction and recovery, while as of October 2017 the US government had provided 105 millions of US dollars (according to USAID, the United States Agency for International Development). ${ }^{37}$ The effects of Hurricane Matthew are still ongoing, and the International Fund

\footnotetext{
${ }^{37} \mathrm{RCF}$ consists of an outright loan disbursement to countries facing an urgent balance of payments need,
} 
for Agricultural Development (IFAD, an international financial institution and specialized United Nations agency) on August 2018 announced it would invest 11 millions of US dollars to help restore agricultural productivity in some the worst affected areas of the island nation (link here). Keeping in mind that these interventions have typically a loan component and are spread out over a number of years, they are far less than what our simulations suggest is needed to eliminate welfare losses.

Let us now pick a more moderate grant amount and disburse it over different time horizons so that we can assess how the dynamics of loan disbursement affect the welfare gains. The amount is chosen to reduce the welfare loss by a fifth in the no-persistence case (from 1.59 to 1.27 in consumption-equivalent terms). In practice, we fix the reaction parameter $\rho_{\phi d}$ to 17.5 , which implies a yearly average grant equal to $0.58 \%$ of GDP, or equivalently, about 47 millions of US dollars every year for the average disaster-prone country, an amount closer to what is observed in the data. Panel (b) of Figure 6 shows that welfare gains (in percent of the $20 \%$ welfare gain obtained by disbursing the grant equal to $0.58 \%$ of GDP) are monotonically decreasing in the persistence of grants. In fact, given discounting in the welfare calculation, it is optimal to immediately disburse the entire grant rather than spreading it out over time. ${ }^{38}$ Nevertheless, the decrease in welfare gains observed in Panel (b) are at least one order of magnitude smaller than the increase in welfare gains reported in Panel (a). This suggests that what is critical for sustaining welfare in disaster-prone countries is the amount of grant, while the dynamics of the disbursement is of second-order importance.

All in all, our results suggest that post-disaster grants play an important role in mitigating the welfare losses of disaster-prone countries. However, typical commitments of international donors fall short of what is needed to significantly reduce welfare losses.

\subsection{Ex-Ante Public Investment in Resilient Capital}

We now turn to studying the effects of resilient infrastructure. As outlined in Section 3.3, investing in resilient capital provides shelter against natural disasters since this is not destroyed. The flip side is that this type of capital is more expensive than standard capital, hence the government has to bear an additional fiscal cost, ultimately paid for by households via current and future taxes, unless donors contribute to the financing of the extra cost of investing in resilience. We follow IMF (2019a) and Bonato et al. (2019) in assuming that investment in resilient capital is $25 \%$ more expensive than investment in standard public

with a 10-year maturity and zero interest rate (source: IMF). These are therefore not grants but concessional loans, so the recipient still has to pay back the principal.

${ }^{38}$ Obviously, we abstract from capacity and other constraints in managing large amount of grants in developing countries, which might point towards some degree of inertia in their disbursement. 
Figure 7: Welfare Effects of Investment in Resilient Capital in Disaster-Prone Countries.

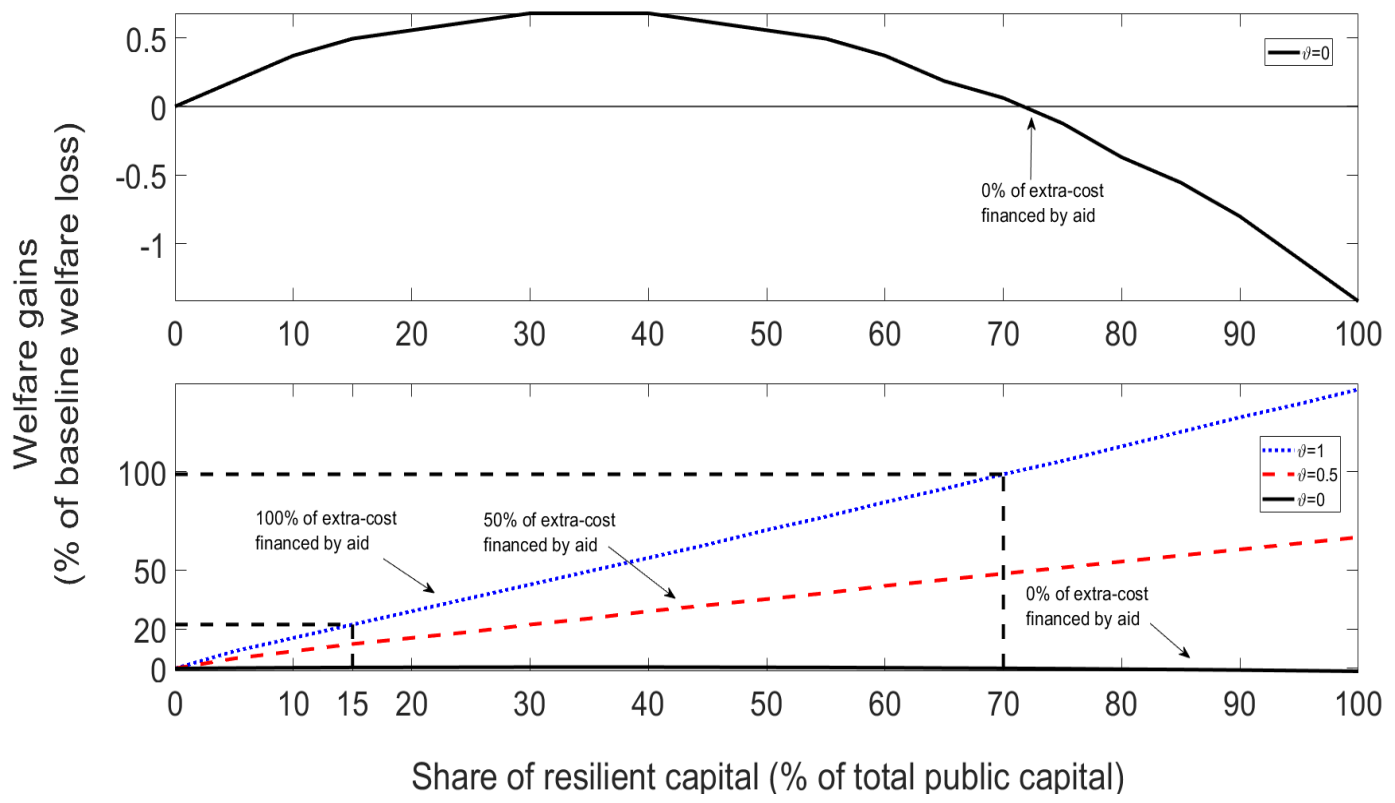

Notes: Welfare gains in the top panel are calculated as the percentage difference between the welfare loss in the baseline calibration and the welfare losses under different shares of resilient capital in the total public capital stock when there is no international aid financing the extra cost of investment in resilience $(\vartheta=0)$. Welfare gains in the bottom panel are calculated as the percentage difference between the welfare loss in the baseline calibration and the welfare losses under different shares of resilient capital in the total public capital stock with different international aid financing the extra cost of investment in resilience $(\vartheta=\{0,0.5,1\})$.

capital by setting $\iota=0.25 .{ }^{39}$

In our first experiment, disaster-prone countries invest in resilient capital by self-financing the extra cost $\iota$ (by setting $\vartheta=0$ ). The top panel of Figure 7 shows that welfare gains from investing in resilience are tiny if disaster-prone countries have to fully bear its extra cost. Moreover, above a certain threshold of the share of resilient capital in the total public capital stock (35\%), welfare gains start decreasing and eventually turn negative, i.e. creating welfare losses. This is explained by the increase in government expenditure which in turn requires tax rises to keep public debt stable at the expense of private consumption and investment.

However, if donors step in by financing, say, half or the entire extra cost of resilience $(\vartheta=\{0.5,1\})$, the picture remarkably improves. Indeed, disaster-prone countries experience increasing welfare gains by making a larger fraction of the public capital stock resilient to natural disasters, as visible from the lower panel of Figure 7. Moreover, if donors finance the entire extra cost of resilience, disaster-prone countries may completely eliminate the welfare loss from natural disasters by reaching a share of resilient capital of about $70 \%$.

\footnotetext{
${ }^{39} \mathrm{We}$ also assume that the government reacts in the same way to deviations of the stock of resilient capital from steady state as for standard public capital, i.e. we set $\rho_{x g a}=0.80$.
} 
This amounts to a yearly grant of $1.06 \%$ of GDP or about 87 millions of US dollars, using again the average GDP in disaster-prone countries (in constant 2010 USD). Remarkably, relative to receiving a grant only in the aftermath of natural disasters (shown in the previous subsection), to eliminate the welfare loss from natural disasters a grant amount of less than a half is needed ex-ante. This is explained by the much more muted loss of capital, output and welfare observed in response to a disaster, when resilient infrastructure is in place. In contrast, if aid is disbursed in the aftermath of disasters and infrastructure is not resilient, the disaster-induced loss of capital occurs to a full extent, generating larger output and welfare losses.

Moreover, even if we consider less ambitious international aid that reduces the welfare loss only by a fifth (as in the previous subsection), by reaching a $15 \%$ share of resilient capital in the total public capital stock, ex-ante grants are more effective than ex-post intervention. These amount to about 5 millions of US dollars every year compared to the 47 millions of US dollars needed post-natural-disaster

These result carry crucial policy implications. First, disaster-prone countries alone cannot improve welfare significantly by investing in and self-financing resilient capital. International aid is crucial to improve their welfare. Second, international aid is more effective when it finances ex-ante investment in resilient capital rather than accruing only in the aftermath of natural disasters. To help disaster-prone countries reach a given level of welfare via grants that finance the extra cost of resilient infrastructure, donors have to disburse less than a half the resources required to finance post-disaster intervention. Furthermore, ex-ante donor support, tied to investment in resilience, carries also the potential benefit of reducing the scope for moral hazard problems, relative to ex-post intervention. In fact, countries may lack incentives to build resilience if they expect aid to be disbursed in the aftermath of a disaster.

\section{Conclusions}

By using a DSGE model augmented with natural disasters shocks and solved using Taylor projection, we assess the long-term macroeconomic and welfare effects of climate-changerelated weather shocks in disaster-prone countries. We find that natural disasters severely weigh on the growth and development path of small and low-income economies relative to peer developing economies and severely impact their welfare.

Our results suggest that only due to being subject to more frequent and powerful natural disasters, disaster-prone countries grow on average by 1 percent less a year than their nondisaster-prone peers, thus experiencing a divergence process. On average, disaster-prone countries have a public debt 1.54 percentage points of GDP higher than non-disaster-prone 
countries, thus posing risks to their public finance sustainability. Moreover, disaster-prone countries suffer sizable welfare losses, with a permanent reduction in consumption of 1.6 percent relative to non-disaster-prone ones. Insofar climate change continues to increase the magnitude and frequency of natural disasters, such negative macroeconomic and welfare outcomes may become increasingly worse. Indeed, we find that climate change may make the gap in GDP growth three times larger, while public debt and welfare losses may be increased by a factor of nine and seven, respectively.

Disaster-prone countries that invest in public infrastructure resilient to natural disasters can improve their welfare provided that international donors contribute, at least in part, to finance its higher cost relative to standard infrastructure. Therefore, our main policy finding is that international aid can improve welfare in disaster-prone countries but it is more effective when it finances ex-ante investment in resilient public infrastructure rather than accruing only in the aftermath of natural disasters. Indeed, to eliminate the welfare losses from natural disasters via grants that finance the extra cost of resilient infrastructure, donors have to disburse less than a half the amount required to finance post-disaster intervention.

\section{References}

Anthoff, D. and Tol, R. (2014). The climate framework for uncertainty, negotiation and distribution (FUND). Technical Descritpion Version 3.9.

Araujo, J. D., Li, B. G., Poplawski-Ribeiro, M., and Zanna, L.-F. (2016). Current account norms in natural resource rich and capital scarce economies. Journal of Development Economics, 120:144 - 156 .

Barro, R. J. (2009). Rare disasters, asset prices, and welfare costs. American Economic Review, 99(1):243-64.

Barro, R. J. (2015). Environmental protection, rare disasters and discount rates. Economica, 82(325):1-23.

Bevan, D. L. and Adam, C. (2016). Financing the reconstruction of public capital after a natural disaster. Policy Research Working Paper Series 7718, The World Bank.

Bi, H., Shen, W., and Yang, S.-C. S. (2016). Fiscal limits in developing countries: a DSGE approach. Journal of Macroeconomics, 49:119 - 130.

Bonato, L., Cantelmo, A., Melina, G., and Salinas, G. (2019). Policy trade-offs in building resilience to natural disasters: the case of St. Lucia. IMF Working Papers 19/54, International Monetary Fund.

Borensztein, E., Cavallo, E., and Jeanne, O. (2017). The welfare gains from macro-insurance against natural disasters. Journal of Development Economics, 124:142 - 156.

Brown, P., Daigneault, A. J., Tjernström, E., and Zou, W. (2018). Natural disasters, social protection, and risk perceptions. World Development, 104:310 - 325.

Burke, M., Solomon M., H., and Miguel, E. (2015). Global non-linear effect of temperature on economic production. Nature, $527(15725)$. 
Cai, Y., Judd, K. L., and Lontzek, T. S. (2017). The social cost of carbon with economic and climate risks. Economics Working Papers 18113, Hoover Institution.

Caldara, D., Fernandez, J., Rubio-Ramirez, J., and Yao, W. (2012). Computing DSGE models with recursive preferences and stochastic volatility. Review of Economic Dynamics, 15(2):188-206.

Cameron, L. and Shah, M. (2015). Risk-taking behavior in the wake of natural disasters. Journal of Human Resources, 50(2):484-515.

Carleton, T. A. and Hsiang, S. M. (2016). Social and economic impacts of climate. Science, 353(6304).

Cassar, A., Healy, A., and von Kessler, C. (2017). Trust, risk, and time preferences after a natural disaster: experimental evidence from Thailand. World Development, 94(C):90-105.

Christiano, L. J., Eichenbaum, M., and Evans, C. L. (2005). Nominal rigidities and the dynamic effects of a shock to monetary policy. Journal of Political Economy, 113(1):1-45.

Coenen, G., Straub, R., and Trabandt, M. (2013). Gauging the effects of fiscal stimulus packages in the euro area. Journal of Economic Dynamics and Control, 37(2):367-386.

Dang, D. A. (2012). On the sources of risk preferences in rural Vietnam. MPRA Paper 38738, University Library of Munich, Germany.

Dell, M., Jones, B. F., and Olken, B. A. (2014). What do we learn from the weather? The new climate-economy literature. Journal of Economic Literature, 52(3):740-798.

Donadelli, M., Juppner, M., Riedel, M., and Schlag, C. (2017). Temperature shocks and welfare costs. Journal of Economic Dynamics and Control, 82(C):331-355.

Epstein, L. G. and Zin, S. E. (1989). Substitution, risk aversion, and the temporal behavior of consumption and asset returns: A theoretical framework. Econometrica, 57(4):937-969.

Fernandez-Villaverde, J. and Levintal, O. (2018). Solution methods for models with rare disasters. Quantitative Economics, 9(2):903-944.

Fiala, O. (2017). Experiencing Natural Disasters: How This Influences Risk Aversion and Trust, pages 43-83. Springer International Publishing, Cham.

Garcia-Cicco, J., Pancrazi, R., and Uribe, M. (2010). Real business cycles in emerging countries? American Economic Review, 100(5):2510-31.

Golosov, M., Hassler, J., Krusell, P., and Tsyvinski, A. (2014). Optimal taxes on fossil fuel in general equilibrium. Econometrica, 82(1):41-88.

Gourio, F. (2012). Disaster risk and business cycles. American Economic Review, 102(6):2734-2766.

Hassler, J., Krusell, P., and Smith, A. (2016). Environmental Macroeconomics Chapter 24. volume 2 of Handbook of Macroeconomics, pages 1893 - 2008. Elsevier.

Heal, G. (2017). The economics of the climate. Journal of Economic Literature, 55(3):104663.

Heal, G. and Park, J. (2016). Temperature stress and the direct impact of climate change: A review of an emerging literature. Review of Environmental Economics and Policy, 10(2):117.

Hope, C. (2011). The PAGE09 Integrated Assessment Model: A Technical Description. Working Paper 4/2011, Cambridge Judge Business School.

Intergovernmental Panel on Climate Change (2014). Climate Change 2014: Impacts, Adaptation, and Vulnerability. Part A: Global and Sectoral Aspects. Contribution of working group ii to the fifth assessment report of the intergovernmental panel on climate change. 
International Monetary Fund (2016). Small states' resilience to natural disasters and climate change - role for the IMF. Imf policy paper.

International Monetary Fund (2017). The effects of weather shocks on economic activity: how can low income countries cope? World economic outlook, International Monetary Fund.

International Monetary Fund (2019a). Building ex-ante resilience to natural disasters. Eastern Caribbean Currency Union: Selected Issues Paper IMF Country Report 19/63, International Monetary Fund.

International Monetary Fund (2019b). Building Resilience in Developing Countries Vulnerable to Large Natural Disasters. Imf policy paper.

Isoré, M. and Szczerbowicz, U. (2017). Disaster risk and preference shifts in a New Keynesian model. Journal of Economic Dynamics and Control, 79(C):97-125.

Judd, K. L. (1992). Projection methods for solving aggregate growth models. Journal of Economic Theory, 58(2):410-452.

Kling, G., Lo, Y. C., Murinde, V., and Volz, U. (2018). Climate vulnerability and the cost of debt. Working Paper Series 12/2018, Centre for Global Finance, SOAS University of London.

Levintal, O. (2018). Taylor projection: A new solution method for dynamic general equilibrium models. International Economic Review, 59(3):1345-1373.

Marto, R., Papageorgiou, C., and Klyuev, V. (2018). Building resilience to natural disasters: An application to small developing states. Journal of Development Economics, 135(C):574586.

Nordhaus, W. (2019). Climate change: the ultimate challenge for economics. American Economic Review, 109(6):1991-2014.

Nordhaus, W. D. (1992). The 'DICE' model: background and structure of a Dynamic Integrated Climate-Economy Model of the Economics of Global Warming. Cowles Foundation Discussion Papers 1009, Cowles Foundation for Research in Economics, Yale University.

Nordhaus, W. D. and Yang, Z. (1996). A regional dynamic general-equilibrium model of alternative climate-change strategies. American Economic Review, 86(4):741-765.

Schmitt-Grohé, S. and Uribe, M. (2007). Optimal simple and implementable monetary and fiscal rules. Journal of Monetary Economics, 54(6):1702-1725.

Schmitt-Grohé, S. and Uribe, M. (2017). Open Economy Macroeconomics. Princeton University Press.

Schmitt-Grohé, S. and Uribe, M. (2018). How important are terms-of-trade shocks? International Economic Review, 59(1):85-111.

Schubert, S. F. and Turnovsky, S. J. (2011). The impact of oil prices on an oil-importing developing economy. Journal of Development Economics, 94(1):18 - 29.

Shen, W., Yang, S.-C. S., and Zanna, L.-F. (2018). Government spending effects in lowincome countries. Journal of Development Economics, 133:201 - 219.

Standard \& Poor's (2015). Storm Alert: Natural Disasters Can Damage Sovereign Creditworthiness. Technical report.

Tallarini Jr., T. D. (2000). Risk-sensitive real business cycles. Journal of Monetary Economics, 45(3):507-532.

Tol, R. S. J. (2009). The economic effects of climate change. Journal of Economic Perspectives, 23(2):29-51. 
Traeger, C. P. (2014). Why uncertainty matters: discounting under intertemporal risk aversion and ambiguity. Economic Theory, 56(3):627-664.

Uribe, M. and Yue, V. Z. (2006). Country spreads and emerging countries: Who drives whom? Journal of International Economics, 69(1):6-36.

van den Berg, M., Fort, R., and Burger, K. (2009). Natural hazards and risk aversion: experimental evidence from Latin America. Technical report.

van der Ploeg, F. and de Zeeuw, A. (2018). Climate tipping and economic growth: Precautionary capital and the price of carbon. Journal of the European Economic Association, 16(5):1577-1617.

Vissing-Jorgensen, A. and Attanasio, O. P. (2003). Stock-market participation, intertemporal substitution, and risk-aversion. American Economic Review, 93(2):383-391.

Zubairy, S. (2014). On fiscal multipliers: estimates from a medium scale DSGE model. International Economic Review, 55(1):169-195. 


\section{Appendix}

This Appendix provides detailed information about the empirical evidence on natural disasters and the model.

Appendix A shows the distribution of EMDEs according to the annual probability of experiencing a natural disaster. Tables A.1-A.4 report details about each of the four quartiles of the distribution. We label the top quartile disaster-prone countries, while the remaining three are labeled non-disaster-prone countries.

Appendix B reports information about the 20 most damaging natural disasters in our dataset, ordered from the largest to the smallest.

Appendix C reports the equations of the stationary DSGE model. 


\section{A Country Distribution and Statistics on Natural Disas- ters}

Table A.1: Disaster-Prone Countries: Fourth Quartile (75\%-100\%) of the Annual Probability Distribution of Natural Disasters.

\begin{tabular}{|c|c|c|c|c|}
\hline \multirow[t]{2}{*}{ Country } & \multirow{2}{*}{$\begin{array}{l}\text { Annual Probability } \\
\text { per } 1000 \text { sq. km (\%) }\end{array}$} & \multicolumn{2}{|c|}{ Damages (\% of GDP) } & \multirow[t]{2}{*}{ Small economy } \\
\hline & & Average & $\operatorname{Max}$ & \\
\hline Marshall Islands & 100.00 & 2.72 & 2.72 & Yes* $^{*}$ \\
\hline St. Vincent and the Grenadines & 100.00 & 4.57 & 15.0 & Yes* \\
\hline Tuvalu & 100.00 & N.A. & N.A. & Yes* \\
\hline Micronesia, Fed. Sts. & 50.00 & 1.85 & 3.49 & Yes* \\
\hline St. Lucia & 48.39 & 1.07 & 3.13 & Yes* \\
\hline Tonga & 46.67 & 12.2 & 29.0 & Yes* \\
\hline Grenada & 44.12 & 74.8 & 148 & Yes* \\
\hline Dominica & 33.33 & 118 & 260 & Yes* \\
\hline Kiribati & 24.69 & N.A. & N.A. & Yes* \\
\hline Maldives & 16.67 & N.A. & N.A. & Yes* \\
\hline Comoros & 10.75 & 0.84 & 0.84 & Yes* \\
\hline Mauritius & 9.80 & 1.69 & 4.03 & Yes* \\
\hline Samoa & 8.80 & 8.58 & 16.6 & Yes* \\
\hline Jamaica & 5.91 & 1.41 & 8.82 & No \\
\hline Gambia & 5.31 & N.A. & N.A. & Yes** \\
\hline Cabo Verde & 4.96 & 0.07 & 0.07 & Yes* \\
\hline Fiji & 4.11 & 1.70 & 12.9 & Yes* \\
\hline Vanuatu & 4.10 & 30.2 & 60.1 & Yes* \\
\hline Haiti & 3.60 & 3.69 & 25.1 & Yes ${ }^{* *}$ \\
\hline El Salvador & 3.33 & 1.87 & 5.33 & No \\
\hline Macedonia, FYR & 2.72 & 0.44 & 0.86 & No \\
\hline Burundi & 2.69 & 0.24 & 0.42 & Yes** \\
\hline Rwanda & 2.47 & 0.00 & 0.00 & Yes** \\
\hline Swaziland & 2.30 & 0.00 & 0.00 & Yes* \\
\hline Belize & 1.96 & 12.8 & 33.4 & Yes* \\
\hline Lebanon & 1.91 & N.A. & N.A. & No \\
\hline Montenegro & 1.81 & N.A. & N.A. & Yes* \\
\hline Dominican Republic & 1.75 & 1.03 & 9.14 & No \\
\hline Albania & 1.74 & 0.16 & 0.39 & No \\
\hline Solomon Islands & 1.73 & 0.80 & 2.04 & Yes* \\
\hline Timor-Leste & 1.68 & N.A. & N.A. & Yes* \\
\hline Costa Rica & 1.57 & 0.21 & 0.67 & No \\
\hline Sri Lanka & 1.52 & 0.24 & 1.47 & No \\
\hline Moldova & 1.33 & 2.47 & 9.22 & No \\
\hline
\end{tabular}

Sources: EM-DAT and authors' calculations.

Notes: Countries are ordered by the annual probability of a natural disaster per 1000 squared kilometers over the sample 1998-2017. EM-DAT provides damages in US dollars. Damages in percent of GDP are obtained dividing damages by GDP of the year of the event. Damages (\% of GDP) are computed for each country by using data for each single event over the sample 1998-2017. Small economies comprise small states and low-income countries.

* Denotes Small states which are countries with a population below 1.5 million that are not advanced economies or high-income oil exporting countries (IMF).

** Denotes Low-income-countries which are countries with a GNI per capita below $\$ 995$ in 2017 (World Bank). 
Table A.2: Non-Disaster-Prone Countries: Third Quartile (50\%-75\%) of the Annual Probability Distribution of Natural Disasters.

\begin{tabular}{|c|c|c|c|c|}
\hline \multirow[t]{2}{*}{ Country } & \multirow{2}{*}{$\begin{array}{l}\text { Annual Probability } \\
\text { per } 1000 \text { sq. km (\%) }\end{array}$} & \multicolumn{2}{|c|}{ Damages (\% of GDP) } & \multirow[t]{2}{*}{ Small economy } \\
\hline & & Average & $\operatorname{Max}$ & \\
\hline Djibouti & 1.29 & N.A. & N.A. & Yes* \\
\hline Bosnia and Herzegovina & 1.17 & 1.85 & 2.87 & No \\
\hline Lesotho & 1.15 & N.A. & N.A. & No \\
\hline Guinea-Bissau & 0.97 & N.A. & N.A. & Yes** \\
\hline Armenia & 0.84 & 1.93 & 5.23 & No \\
\hline Guatemala & 0.83 & 0.97 & 3.86 & No \\
\hline Honduras & 0.80 & 7.64 & 72.9 & No \\
\hline Cuba & 0.73 & 2.64 & 7.77 & No \\
\hline Malawi & 0.72 & 1.64 & 6.12 & Yes ${ }^{* *}$ \\
\hline Georgia & 0.72 & 1.47 & 6.54 & No \\
\hline Togo & 0.70 & N.A. & N.A. & Yes ${ }^{* *}$ \\
\hline Tajikistan & 0.70 & 2.44 & 16.3 & Yes ${ }^{* *}$ \\
\hline Sierra Leone & 0.69 & 0.79 & 0.79 & Yes ${ }^{* *}$ \\
\hline Nicaragua & 0.69 & 3.56 & 21.3 & No \\
\hline Nepal & 0.68 & 0.34 & 2.43 & Yes ${ }^{* *}$ \\
\hline Bangladesh & 0.67 & 1.30 & 8.60 & No \\
\hline Korea, Dem. People's Rep. & 0.66 & N.A. & N.A. & Yes ${ }^{* *}$ \\
\hline Bulgaria & 0.59 & 0.37 & 1.54 & No \\
\hline Bhutan & 0.52 & 0.87 & 0.87 & Yes* \\
\hline Serbia & 0.45 & 2.45 & 4.63 & No \\
\hline Cambodia & 0.44 & 1.36 & 4.35 & No \\
\hline Senegal & 0.41 & 0.46 & 0.84 & Yes $^{* *}$ \\
\hline Romania & 0.40 & 0.45 & 1.34 & No \\
\hline Benin & 0.39 & 0.01 & 0.01 & Yes $^{* *}$ \\
\hline Uganda & 0.35 & 0.01 & 0.02 & Yes ${ }^{* *}$ \\
\hline Philippines & 0.33 & 0.21 & 3.73 & No \\
\hline Vietnam & 0.30 & 0.44 & 3.49 & No \\
\hline Burkina Faso & 0.29 & 0.70 & 1.79 & Yes $^{* *}$ \\
\hline Azerbaijan & 0.29 & 1.33 & 0.90 & No \\
\hline Malaysia & 0.27 & 0.08 & 0.50 & No \\
\hline
\end{tabular}

Sources: EM-DAT and authors' calculations.

Notes: Countries are ordered by the annual probability of a natural disaster per 1000 squared kilometers over the sample 1998-2017. EM-DAT provides damages in US dollars. Damages in percent of GDP are obtained dividing damages by GDP of the year of the event. Damages (\% of GDP) are computed for each country by using data for each single event over the sample 1998-2017. Small economies comprise small states and low-income countries.

* Denotes Small states which are countries with a population below 1.5 million that are not advanced economies or high-income oil exporting countries (IMF).

** Denotes Low-income-countries which are countries with a GNI per capita below $\$ 995$ in 2017 (World Bank). 
Table A.3: Non-Disaster-Prone Countries: Second Quartile (25\%-50\%) of the Annual Probability Distribution of Natural Disasters.

\begin{tabular}{|c|c|c|c|c|}
\hline \multirow[t]{2}{*}{ Country } & \multirow{2}{*}{$\begin{array}{l}\text { Annual Probability } \\
\text { per } 1000 \text { sq. km (\%) }\end{array}$} & \multicolumn{2}{|c|}{ Damages ( $\%$ of GDP) } & \multirow[t]{2}{*}{ Small economy } \\
\hline & & Average & Max & \\
\hline Liberia & 0.27 & N.A. & N.A. & Yes** \\
\hline Guinea & 0.26 & N.A. & N.A. & Yes $^{* *}$ \\
\hline Ecuador & 0.25 & 0.34 & 1.62 & No \\
\hline Lao PDR & 0.25 & 0.57 & 1.71 & No \\
\hline Ghana & 0.25 & 0.15 & 0.27 & No \\
\hline Congo, Dem. Rep. & 0.23 & 0.04 & 0.04 & Yes $^{* *}$ \\
\hline Paraguay & 0.20 & 0.06 & 0.22 & No \\
\hline Belarus & 0.19 & 0.10 & 0.24 & No \\
\hline Syrian Arab Republic & 0.19 & N.A. & N.A. & Yes** \\
\hline Thailand & 0.19 & 0.56 & 10.9 & No \\
\hline Kenya & 0.17 & 0.07 & 0.20 & No \\
\hline Eritrea & 0.17 & N.A. & N.A. & Yes** \\
\hline Jordan & 0.17 & N.A. & N.A. & No \\
\hline Morocco & 0.16 & 0.42 & 2.16 & No \\
\hline Zimbabwe & 0.15 & 1.30 & 3.49 & Yes ${ }^{* *}$ \\
\hline Madagascar & 0.15 & 1.32 & 5.73 & Yes $^{* *}$ \\
\hline Afghanistan & 0.15 & 0.18 & 0.79 & Yes** \\
\hline Papua New Guinea & 0.15 & 0.55 & 1.24 & No \\
\hline Guyana & 0.14 & 15.9 & 35.5 & Yes* \\
\hline Cameroon & 0.14 & 0.01 & 0.01 & No \\
\hline Somalia & 0.13 & 0.03 & 0.03 & Yes** \\
\hline Central African Republic & 0.13 & N.A. & N.A. & Yes** $^{* *}$ \\
\hline Myanmar & 0.13 & 1.84 & 12.6 & No \\
\hline Pakistan & 0.13 & 0.60 & 5.35 & No \\
\hline Cote d'Ivoire & 0.12 & N.A. & N.A. & No \\
\hline Tunisia & 0.12 & N.A. & N.A. & No \\
\hline Ukraine & 0.12 & 0.23 & 0.96 & No \\
\hline Mozambique & 0.11 & 1.30 & 8.38 & Yes $^{* *}$ \\
\hline Turkey & 0.11 & 0.09 & 0.36 & No \\
\hline Nigeria & 0.10 & 0.02 & 0.11 & No \\
\hline Iraq & 0.10 & 0.00 & 0.00 & No \\
\hline
\end{tabular}

Sources: EM-DAT and authors' calculations.

Notes: Countries are ordered by the annual probability of a natural disaster per 1000 squared kilometers over the sample 1998-2017. EM-DAT provides damages in US dollars. Damages in percent of GDP are obtained dividing damages by GDP of the year of the event. Damages (\% of GDP) are computed for each country by using data for each single event over the sample 1998-2017. Small economies comprise small states and low-income countries.

* Denotes Small states which are countries with a population below 1.5 million that are not advanced economies or high-income oil exporting countries (IMF).

** Denotes Low-income-countries which are countries with a GNI per capita below $\$ 995$ in 2017 (World Bank). 
Table A.4: Non-Disaster-Prone Countries: First Quartile (0\%-25\%) of the Annual Probability Distribution of Natural Disasters.

\begin{tabular}{|c|c|c|c|c|}
\hline \multirow[t]{2}{*}{ Country } & \multirow{2}{*}{$\begin{array}{l}\text { Annual Probability } \\
\text { per } 1000 \text { sq. km (\%) }\end{array}$} & \multicolumn{2}{|c|}{ Damages ( $\%$ of GDP) } & \multirow[t]{2}{*}{ Small economy } \\
\hline & & Average & $\operatorname{Max}$ & \\
\hline Namibia & 0.10 & 0.25 & 0.51 & No \\
\hline Colombia & 0.09 & 0.11 & 0.69 & No \\
\hline Bolivia & 0.09 & 1.01 & 4.50 & No \\
\hline Zambia & 0.09 & 0.59 & 0.59 & No \\
\hline Tanzania & 0.08 & 0.00 & 0.00 & Yes** \\
\hline South Africa & 0.08 & 0.06 & 0.17 & No \\
\hline Ethiopia & 0.08 & 0.41 & 2.17 & Yes $^{* *}$ \\
\hline Venezuela, RB & 0.08 & 0.66 & 3.22 & No \\
\hline Niger & 0.07 & 0.91 & 2.65 & Yes** \\
\hline Peru & 0.07 & 0.52 & 1.51 & No \\
\hline Angola & 0.07 & 0.06 & 0.11 & No \\
\hline Mali & 0.06 & N.A. & N.A. & Yes** \\
\hline Suriname & 0.06 & N.A. & N.A. & Yes* \\
\hline Botswana & 0.06 & 0.20 & 0.30 & No \\
\hline Mauritania & 0.06 & 0.03 & 0.03 & No \\
\hline Gabon & 0.06 & N.A. & N.A. & No \\
\hline Indonesia & 0.05 & 0.09 & 1.36 & No \\
\hline Mexico & 0.05 & 0.11 & 0.90 & No \\
\hline Iran, Islamic Rep. & 0.05 & 0.27 & 2.90 & No \\
\hline Chad & 0.04 & 0.07 & 0.08 & Yes $^{* *}$ \\
\hline Sudan & 0.04 & 0.42 & 1.04 & Yes** \\
\hline Uzbekistan & 0.03 & 0.36 & 0.36 & No \\
\hline Algeria & 0.03 & 0.17 & 0.55 & No \\
\hline India & 0.03 & 0.15 & 0.81 & No \\
\hline Egypt, Arab Rep. & 0.03 & 0.02 & 0.03 & No \\
\hline Mongolia & 0.03 & 2.10 & 7.04 & No \\
\hline Kazakhstan & 0.02 & 0.03 & 0.10 & No \\
\hline Congo, Rep. & 0.01 & 0.00 & 0.00 & No \\
\hline Brazil & 0.01 & 0.03 & 0.25 & No \\
\hline China & 0.01 & 0.16 & 3.08 & No \\
\hline Russian Federation & 0.01 & 0.04 & 0.29 & No \\
\hline Libya & 0.00 & N.A. & N.A. & No \\
\hline
\end{tabular}

Sources: EM-DAT and authors' calculations.

Notes: Countries are ordered by the annual probability of a natural disaster per 1000 squared kilometers over the sample 1998-2017. EM-DAT provides damages in US dollars. Damages in percent of GDP are obtained dividing damages by GDP of the year of the event. Damages (\% of GDP) are computed for each country by using data for each single event over the sample 1998-2017. Small economies comprise small states and low-income countries.

* Denotes Small states which are countries with a population below 1.5 million that are not advanced economies or high-income oil exporting countries (IMF).

** Denotes Low-income-countries which are countries with a GNI per capita below $\$ 995$ in 2017 (World Bank). 


\section{B The Most Damaging Natural Disasters}

Table B.1: The 20 Most Damaging Natural Disasters (1998-2017).

\begin{tabular}{lcclccc}
\hline Country & Year & Type & Name & $\begin{array}{c}\text { Damages } \\
(\% \\
\text { of GDP })\end{array}$ & $\begin{array}{c}\text { Disaster } \\
\text {-prone } \\
\text { country }\end{array}$ & $\begin{array}{c}\text { Small } \\
\text { economy }\end{array}$ \\
\hline Dominica & 2017 & Storm & Hurricane Maria & 260 & Yes & Yes* \\
Grenada & 2004 & Storm & Hurricane Ivan & 148 & Yes & Yes* \\
Dominica & 2015 & Storm & Tropical Storm Erika & 90.2 & Yes & Yes* \\
Honduras & 1998 & Storm & Hurricane Mitch & 72.9 & No & No \\
Vanuatu & 2015 & Storm & Cyclone Pam & 60.1 & Yes & Yes* \\
Guyana & 2005 & Flood & N.A. & 35.5 & No & Yes* \\
Belize & 2000 & Storm & Hurricane Keith & 33.4 & Yes & Yes* \\
Tonga & 2001 & Storm & Tropical Cyclone Waka & 29.0 & Yes & Yes* \\
Belize & 2001 & Storm & Hurricane Iris & 28.7 & Yes & Yes* \\
Haiti & 2016 & Storm & Hurricane Matthew & 25.1 & Yes & Yes** \\
Nicaragua & 1998 & Storm & Hurricane Mitch & 21.3 & No & No \\
Samoa & 2012 & Storm & Cyclone Evan & 16.6 & Yes & Yes* \\
Tajikistan & 2008 & Ex. Temp. & N.A. & 16.3 & Yes & Yes** \\
St. Vin.Gr. & 2013 & Flood & N.A. & 15.0 & Yes & Yes* \\
Fiji & 2016 & Storm & Tropical Storm Winston & 12.9 & Yes & Yes* \\
Myanmar & 2008 & Storm & Cyclone Nargis & 12.6 & No & No \\
Guyana & 2006 & Flood & N.A. & 11.6 & No & Yes* \\
Thailand & 2011 & Flood & N.A. & 10.9 & No & No \\
Moldova & 2007 & Drought & N.A. & 9.22 & Yes & No \\
Dominican R. & 1998 & Storm & Hurricane Georges & 9.14 & Yes & No \\
\hline
\end{tabular}

Sources: EM-DAT and authors' calculations.

Notes: Countries are ordered by the annual probability of a natural disaster per 1000 squared kilometers over the sample 1998-2017. EM-DAT provides damages in US dollars. Damages in percent of GDP are obtained dividing damages by GDP of the year of the event. Damages (\% of GDP) are computed for each country by using data for each single event over the sample 1998-2017. Small economies comprise small states and low-income countries.

* Denotes Small states which are countries with a population below 1.5 million that are not advanced economies or high-income oil exporting countries (IMF).

** Denotes Low-income-countries which are countries with a GNI per capita below $\$ 995$ in 2017 (World Bank). 


\section{The Stationary Model}

The model exhibits a stochastic trend growth rate hence we detrend it before finding the solution. In general, variables are detrended by $z_{t}=A_{t}^{\frac{1}{1-\alpha}}$ unless otherwise states. We denote the detrended variable with a $\ll^{\sim} \gg$, i.e. $\tilde{x}_{t}=\frac{x_{t}}{z_{t}}$, while growth rates are denoted by $\mathrm{a} \ll \gg$, i.e. $\hat{x}_{t}=\frac{x_{t}}{x_{t-1}}$. The full detrended system is the following:

$$
\begin{aligned}
& d_{t+1}=\mu^{d}+\left(\epsilon_{d, t+1}-\mu^{d}\right) \\
& \log \theta_{t+1}=\left(1-\rho_{\theta}\right) \log \bar{\theta}+\rho_{\theta} \log \theta_{t}+\sigma_{\theta} \epsilon_{\theta, t+1} \\
& z_{A, t+1}=\sigma_{A} \epsilon_{A, t+1} \\
& \log \hat{A}_{t}=\Lambda_{A}+z_{A, t}-(1-\alpha) d_{t} \theta_{t} \\
& \hat{A}_{t}=\frac{A_{t}}{A_{t-1}} \\
& \log \hat{z}_{t}=\frac{1}{1-\alpha} \log \hat{A}_{t} \\
& \hat{z}_{t}=\frac{z_{t}}{z_{t-1}} \\
& \tilde{U}_{t}=\tilde{c}_{t}\left(1-l_{t}\right)^{\nu} e^{\xi_{t}} \\
& U_{c, t}=\left(1-l_{t}\right)^{\nu} e^{\xi_{t}} \\
& \tilde{U}_{l, t}=-\nu \tilde{c}_{t}\left(1-l_{t}\right)^{\nu-1} e^{\xi_{t}} \\
& \tilde{\lambda}_{t}=(1-\psi) \tilde{U}_{t}^{-\psi} \frac{U_{c, t}}{\left(1+\tau_{t}^{c}\right)} \\
& -\tilde{\lambda}_{t} \tilde{w}_{t}=(1-\psi) \tilde{U}_{t}^{-\psi} \tilde{U}_{l, t} \\
& M_{t+1}=\beta \frac{\tilde{\lambda}_{t+1}}{\tilde{\lambda}_{t}} \hat{z}_{t+1}^{-\psi} \\
& \tilde{q}_{t}=E_{t} M_{t+1} \exp \left(-d_{t+1} \theta_{t+1}\right) \frac{\left[\tilde{r}_{t+1}+\tilde{q}_{t+1}(1-\delta)\right]}{\hat{\mu}_{t+1}} \\
& 1=\tilde{q}_{t}\left[1-S\left[\frac{\tilde{x}_{t}}{\tilde{x}_{t-1}} \hat{z}_{t}\right]-S^{\prime}\left[\frac{\tilde{x}_{t}}{\tilde{x}_{t-1}} \hat{z}_{t}\right] \frac{\tilde{x}_{t}}{\tilde{x}_{t-1}} \hat{z}_{t}\right]+ \\
& +E_{t} M_{t+1} \tilde{q}_{t+1} S^{\prime}\left[\frac{\tilde{x}_{t+1}}{\tilde{x}_{t}} \hat{z}_{t+1}\right]\left(\frac{\tilde{x}_{t+1}}{\tilde{x}_{t}} \hat{z}_{t+1}\right)^{2} \\
& S\left[\frac{\tilde{x}_{t}}{\tilde{x}_{t-1}} \hat{z}_{t}\right]=\frac{\kappa}{2}\left(\frac{\tilde{x}_{t}}{\tilde{x}_{t-1}} \hat{z}_{t}-\hat{z}\right)^{2} \\
& S^{\prime}\left[\frac{\tilde{x}_{t}}{\tilde{x}_{t-1}} \hat{z}_{t}\right]=\kappa\left(\frac{\tilde{x}_{t}}{\tilde{x}_{t-1}} \hat{z}_{t}-\hat{z}\right) \\
& \tilde{y}_{t}=\tilde{c}_{t}+\tilde{x}_{t}+\tilde{g}_{t}+\tilde{x}_{g, t}+[1+(1-\vartheta) \iota] \tilde{x}_{g a, t}+\tilde{n}_{t}^{x}
\end{aligned}
$$




$$
\begin{aligned}
& \tilde{b}_{g, t}=R_{t-1} \frac{\tilde{b}_{g, t-1}}{\hat{z}_{t}}+\tilde{g}+\tilde{x}_{g, t}+[1+(1-\vartheta) \iota] \tilde{x}_{g a, t}-\tau_{t}^{c} \tilde{c}_{t}-\tilde{\phi}_{t} \\
& -\left(\tilde{b}_{g, t}-\frac{\tilde{b}_{g, t-1}}{\hat{z}_{t}}\right)=\tilde{n}_{t}^{x}+\tilde{\phi}_{t}-R_{t-1} \frac{\tilde{b}_{g, t-1}}{\hat{z}_{t}} \\
& R_{t}=R e^{\eta\left(\frac{\tilde{b}_{g, t}}{\tilde{b}_{g}}-1\right)} \\
& \log \left(\frac{\tilde{\phi}_{t}}{\tilde{\phi}}\right)=\rho_{\phi} \log \left(\frac{\tilde{\phi}_{t-1}}{\tilde{\phi}} \frac{\hat{z}}{\hat{z}_{t}}\right)+\left(1-\rho_{\phi}\right) \rho_{\phi d}\left(\frac{d_{t} \theta_{t}}{\bar{d} \bar{\theta}}\right) \\
& \tilde{k}_{t}^{*}=(1-\delta) \tilde{k}_{t}+\left(1-S\left[\frac{\tilde{x}_{t}}{\tilde{x}_{t-1}} \hat{z}_{t}\right]\right) \tilde{x}_{t} \\
& \tilde{k}_{t}=\frac{\tilde{k}_{t-1}^{*}}{\hat{z}_{t}} \exp \left(-d_{t} \theta_{t}\right) \\
& \tilde{k}_{g, t}^{*}=\left(1-\delta_{g}\right) \tilde{k}_{g, t}+\tilde{x}_{g, t} \\
& \tilde{k}_{g, t}=\frac{k_{g, t-1}^{*}}{\hat{z}_{t}} \exp \left(-d_{t} \theta_{t}\right) \\
& \log \left(\frac{\tilde{x}_{g, t}}{\tilde{x}_{g}}\right)=-\rho_{x g} \log \left(\frac{\tilde{k}_{g, t}}{\tilde{k}_{g}}\right) \\
& \tilde{\bar{k}}_{g, t}=\tilde{k}_{g, t}+\tilde{k}_{g a, t-1} \\
& \tilde{k}_{g a, t}=\left(1-\delta_{g}\right) \frac{\tilde{k}_{g a, t-1}}{\hat{z}_{t}}+\tilde{x}_{g a, t} \\
& \log \left(\frac{\tilde{x}_{g a, t}}{\tilde{x}_{g a}}\right)=-\rho_{x g a} \log \left(\frac{\tilde{k}_{g a, t}}{\tilde{k}_{g a}}\right) \\
& \tilde{r}_{t}=\alpha\left(1-\alpha_{g}\right) \frac{\tilde{y}_{t}}{\tilde{k}_{t}} \\
& \tilde{w}_{t}=(1-\alpha) \frac{\tilde{y}_{t}}{l_{t}} \\
& \tilde{y}_{t}=\frac{\hat{A}_{t}}{\hat{z}_{t}}\left[\tilde{\bar{k}}_{g, t}^{\alpha_{g}}\left(\tilde{k}_{t-1}^{*} \exp \left(-d_{t} \theta_{t}\right)\right)^{1-\alpha_{g}}\right]^{\alpha} l_{t}^{1-\alpha}
\end{aligned}
$$

